\title{
Artigos/Articles
}

\section{Análise de padrões de colocações de itens lexicais como identificadores do perfil estilístico tradutório de heart of darkness ${ }^{1}$ \\ Analysis of collocational patterns of lexical items as identifiers of the translational stylistic profile of heart of darkness}

Mayelli Caldas de Castro²

\section{RESUMO}

O objetivo deste artigo é descobrir se os quatro tradutores de Heart of Darkness para o espanhol capturaram os marcadores de temática de incerteza apontados por Stubbs (2003, 2005). A pesquisa se afilia aos Estudos da Tradução Baseados em Corpus (BAKER, 2000; OLOHAN, 2004) e parte dos achados de Stubbs $(2003,2005)$ sobre preferências estilisticas do texto-fonte. A visão de estilo adotada é a de Saldanha (2011) e fez-se uso da metodologia de corpus para a investigação dos itens selecionados. Os resultados mostraram diferenças significativas nas escolhas individuais por padrões de colocações dos itens analisados,

1. Este estudo é um recorte da tese "O perfil estilístico de quatro tradutores de Heart of Darkness para o Espanhol: uma investigação de mudanças de tradução (shifts in Translation) baseada em padrões de itens lexicais de um corpus paralelo" (CASTRO, 2016), desenvolvida no âmbito do Laboratório Experimental de Tradução (LETRA) da FALE/ UFMG.

2. IFES - Instituto Federal do Espírito Santo (Campus Itapina). Espírito Santo - Brasil. http://orcid.org/0000-0003-3283-6833. E-mail: mayellicaldas@gmail.com. 
Mayelli Caldas de Castro

possibilitando a criação de um perfil estilistico individual das traduções e dos tradutores estudados.

Palavras-chave: Estilo do tradutor; padrões de colocações; itens lexicais; perfil estilístico.

\begin{abstract}
This study aims to discover whether the four translators of Heart of Darkness into Spanish have captured the theme markers of vagueness and uncertainty pointed out by Stubbs $(2003,2005)$. The research is based on Corpus-Based Translation Studies (BAKER, 2000; OLOHAN, 2004) and it is motivated by Stubbs' studies (2003, 2005) on stylistic preferences of the source-text. This investigation is based on the concept of style proposed by Saldanha (2011) and corpus methodology was used to look at the chosen lexical items. The results showed significant differences in the individual choices of collocational patterns of the analyzed lexical items, which enabled the creation of an individual stylistic profile of the studied translations and their translators.
\end{abstract}

Keywords: Translator Style; collocational patterns; lexical items; stylistic profile.

\section{Introdução}

O objetivo deste artigo é descobrir se os quatro tradutores de Heart of Darkness para o espanhol capturaram os marcadores de temática de incerteza apontados por Stubbs (2003, 2005). Caso tais marcadores se façam presentes as diferenças entre suas formas de expressar discursivamente a incerteza serão apontadas, para que se possam explicitar quais são os traços dos estilos pessoais dos tradutores. Para tanto, serão identificados os padrões de colocações de itens lexicais com os nódulos alg* e parec* mais recorrentes nos textos traduzidos (TTs) de Heart of Darkness (HOD) para o espanhol, identificando as diferenças entre o uso desses padrões nos TTs entre si e em relação aos padrões de ocorrências das principais colocações com some*/any* e seem* no texto-fonte (TF). Os itens lexicais formados a partir destes nódulos são responsáveis pela construção do tema de incerteza no TF e nos TTs. 
Esta pesquisa pretende mostrar como a análise de padrões de colocações dos itens lexicais estudados podem indicar traços característicos do estilo das traduções e de seus tradutores.

A pesquisa afilia-se aos estudos do estilo da tradução baseados em corpus (BAKER, 2000; OLOHAN, 2004), principalmente aqueles que investigam o estilo de tradução literária por meio de diferenças nas escolhas linguísticas entre tradutores e em comparação com o TF (Toury, 1995; Chesterman, 1997, 2007; Leuven-Zwart, 1989, 1990; Pekkanen, 2010), tendo como base, também, estudos que identificaram o estilo de TTs de HOD como Magalhães e Assis (2010), Magalhães, Castro e Montenegro (2013), Blauth (2015), Montenegro (2015) e Castro (2016).

O estilo é entendido aqui como atributo textual e pessoal (Saldanha, 2011) e para a investigação dos padrões lexicais formados com alg* e parec* foram levados em conta Stubbs (2003, 2005), Sinclair $(1991,2004)$ e Biber et al. (2004). É importante enfatizar que Stubbs $(2005$, p.4) aponta a necessidade de um estudo sistemático de itens léxico-gramaticais e afirma que "Críticos literários tendem a identificar palavras de conteúdo [...] Porém, eles tendem a ignorar muitas palavras gramaticais que denotam imprecisão e incerteza"3.

Nesta pesquisa parte-se da premissa de Stubbs (2003, 2005), a de que muitos críticos literários não dão a devida importância à pesquisa de palavras gramaticais como, por exemplo, o verbo seem. Esses itens podem ser pistas que revelarão algum traço ainda não percebido na obra. Até onde se sabe, não há trabalhos que investiguem itens léxicogramaticais dessa natureza em corpus de TTs de HOD na perspectiva do estilo do tradutor e da tradução. Assim, este estudo pretende investigar os itens léxico-gramaticais que denotam incerteza nas traduções para o espanhol procurando observar se houve alterações nos TTs que possam indicar características estilísticas das traduções e dos tradutores.

As perguntas de pesquisa norteadoras deste trabalho foram:

3. No original "Literary critics tend to identify a few content words [...] However, they tend to ignore the many grammatical words denoting vagueness and uncertainty." Todas as notas que trazem a indicação da língua original são de citações traduzidas pela autora deste artigo. 
1) Quais TTs apresentam maior variedade nas escolhas lexicais

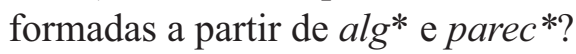

2) Quais são as diferenças nas escolhas individuais dos padrões de ocorrências das principais colocações e/ou agrupamentos lexicais com os nódulos alg* e parec* nos TTs em relação aos padrões de ocorrências das principais colocações com some*/any* e seem* no TF?

3) É possível identificar traços de um perfil estilístico individual dos tradutores de HOD para o espanhol com base nas escolhas léxicogramaticais individuais, no nível microestrutural?

Parte-se da hipótese de que a análise dos padrões de colocações dos itens lexicais possibilitará identificar traços do perfil estilístico tradutório com base nas preferências linguísticas rastreadas nas traduções estudadas, uma vez que os padrões encontrados nos resultados foram considerados proeminentes. Assim, a próxima seção apresenta os principais pressupostos teórico-metodológicos utilizados neste estudo, bem como a motivação para a escolha dos itens lexicais analisados.

\section{Estilo do tradutor e da tradução}

Com a disseminação dos Estudos da Tradução Baseados em Corpus (ETBC) no final da década de 90, observou-se no campo de estudos da tradução uma tentativa de desenvolver uma metodologia para investigação do estilo do tradutor. Baker (2000) apresenta um estudo exploratório inédito para investigar se o tradutor literário possui traços próprios e distintivos de estilo.

Baker (2000) enfatiza que existem vários estudos que buscaram desenvolver noções de estilo se baseando tanto em estudos linguísticos quanto em estudos literários para explicar as escolhas feitas na tradução e, também, com o objetivo prescritivo de criar instruções para a seleção de estratégias de tradução específicas, com base em diversas categorias estilísticas formalizadas baseadas em tipos textuais ou registros.

No entanto, Baker (2000, p. 244) afirma que apesar de estudos interessados no estilo da tradução, tanto da perspectiva literária quanto linguística, não há muito interesse no estilo do tradutor, ou grupo 
de tradutores, nem tampouco a existência de um corpus de material traduzido que pertença a um período histórico específico. Por essas razões e, também, pelo fato de acreditar que não é possível a produção de qualquer extrato da língua sem que o produtor deixe alguma marca pessoal, Baker (2000) propõe estudar o estilo do tradutor com o intuito de identificar sua presença no texto.

Baker (2000, p.245) afirma que a voz do tradutor se faz presente, explicando que esse é o trabalho que mais se aproxima de seu objetivo de investigar a marca deixada pelo tradutor no texto. Incorporando a noção de voz de Hermans (1996) Baker (2000, p. 245) define estilo como impressão digital expressa em uma gama de caraterísticas linguísticas e não linguísticas.

Dessa maneira, Baker (2000) sugere que para investigar a marca deixada pelo tradutor do texto, seu estilo, é necessário investigar a maneira de expressão típica do tradutor, o uso específico que ele faz da língua, seu perfil individual de hábitos linguísticos comparado com outros tradutores. Enfocando a estilística forense, a autora afirma que esse estudo deve buscar padrões recorrentes dos tradutores. Acima de tudo, Baker (2000) objetiva investigar os padrões de escolhas, conscientes ou não.

Baker (2000) faz um estudo usando como base o corpus TEC e o

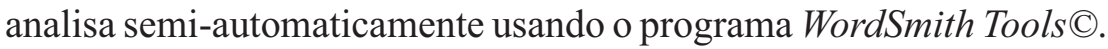
Em seu estudo, a autora apresenta um corpus formado por traduções de dois tradutores literários britânicos, Peter Bush e Peter Clark. A pesquisadora afirma que é preciso explorar a possiblidade de que o tradutor literário pode apresentar uma consistência em relação à preferência por determinados itens lexicais, padrões sintáticos, padrões coesivos e na pontuação. Assim, Baker (2000) investiga alguns aspectos da padronização linguística nas traduções dos referidos tradutores, como a razão forma/item (typeltoken ratio), tamanho médio das sentenças, variações nos textos e a frequência e padronização em relação ao uso do verbo say.

Dentre seus principais achados, a autora observa que Bush apresenta uma razão forma/item maior que a de Clark, o que representa maior variação lexical nas traduções de Bush. Baker (2000, p.257) 
observa que Peter Clark se aproxima mais do inglês "padronizado" usado no inglês traduzido.

Em relação ao número de sentenças, os dados mostraram que Peter Clark apresenta um número menor de sentenças e com menos variação lexical. Baker (2000, p. 251) interpreta esses achados quantitativos gerais como uma tentativa de Peter Clark de mediar os textos árabes, para que eles fiquem mais simples e legíveis para o leitor inglês. Os resultados sobre a utilização do verbo say apontam uma tendência em Peter Clark em usar modificadores com esse verbo, o uso do discurso direto e uso do passado simples na narração, sendo ele o tradutor que mais utiliza este verbo na narrativa. Baker constatou que Peter Clark utilizou o tempo passado simples do verbo say mesmo onde no textofonte foi utilizado o presente, o que, segundo a autora, tem implicações estilísticas, uma vez que altera o nível de formalidade e informalidade da narrativa.

No entanto, Baker (2000, p. 255) faz uma ressalva na discussão dos resultados e afirma que os padrões encontrados precisam ser comparados diretamente com o texto-fonte para analisar melhor a influência da língua-fonte e do autor sobre o estilo do tradutor. A autora reconhece as limitações de seu estudo por não apresentar essa comparação entre texto traduzido e fonte, deixando claro que seu objetivo primordial é propor e desenvolver uma nova metodologia de análise para a investigação do estilo do tradutor.

Além do trabalho de Baker (2000), há também o de Olohan (2004) sobre o estilo e a ideologia dos tradutores, apresentando dois estudos de casos que exploram a metodologia de corpus para a investigação de padrões do comportamento linguístico e intervenções de tradutores específicos. Olohan (2004, p. 147) compara o conceito de estilo proposto por Baker (2000) ao conceito proposto por Leech e Short (1981, p. 11-12) "uma combinação individual de hábitos linguísticos que, de alguma maneira, o denuncia [o autor] em tudo o que escreve", afirmando que as duas noções de estilo possuem muito em comum e que, afinal, a análise quantitativa de corpus e análise qualitativa podem dizer muito sobre o estilo dos tradutores.

4. No original "an individual combination of linguistic habits which somehow betrays [the author] in all that he writes". 
Olohan (2004) defende que a ideologia que está implicitamente codificada pode ser descoberta por meio do estudo de padrões de associação, padrões lexicais e gramaticais, dos quais os usuários da língua podem não estar conscientes. Além disso, de acordo com a noção de ideologia de Fowler (1977), citada por Olohan (2004), o fato de se priorizar algumas escolhas lexicais e gramaticais em detrimento de outras existentes pode constituir-se em indícios de ideologia. Olohan (2004, p.148) chama a atenção para o fato de que alguns estudos priorizam as escolhas gramaticais e que em estudos dessa natureza a comparação do corpus de estudo com um corpus geral pode ser importante na identificação de escolhas linguísticas ideologicamente significantes.

No primeiro estudo de caso, Olohan (2004, p. 153) investiga as formas contratas em duas traduções literárias dos tradutores Peter Bush e Dorothy Blair. Os resultados mostraram que Peter Bush usa mais formas contratas do que Blair e, ao comparar os resultados com corpus de consulta de textos traduzidos e de não traduzidos, ela constatou que os números de formas contratas utilizadas por Blair confirmam os resultados obtidos com o corpus de textos traduzidos, ao passo que Bush parece usar formas contratas em conformidade com os resultados obtidos com o corpus composto com textos do BNC. Ao comparar seus achados com os dados dos textos-fontes e dos autores, bem como com informações do gênero textual, a autora conclui que a variação entre Blair e Bush pode estar condicionada ao gênero literário e à estrutura narrativa dos textos traduzidos.

Relevante para este estudo é o trabalho de Saldanha (2011, 2011b, 2011c) que alerta que muitos trabalhos em estilística tradutória se baseiam em diferentes entendimentos de estilo associados a diferentes abordagens metodológicas, reconhecendo assim que há uma dificuldade em identificar um modelo teórico coerente para guiar as novas pesquisas na área. Para ela, a primeira distinção que se precisa fazer é entre estilo como atributo textual e estilo como atributo pessoal.

A autora afirma que as discussões de estilo na tradução são geralmente apresentadas a partir de uma perspectiva do texto-fonte. Saldanha (2011b, p. 237) aponta três trabalhos que abriram o caminho para o estudo do estilo sob a perspectiva do texto traduzido: Baker (2000), Malmkjaer (2003) e Munday (2008). Malmkjaer (2003) introduz o 
conceito de estilística tradutória enfocando o estilo da tradução, e não do tradutor; Baker (2000) desenvolve uma proposta metodológica para o estudo do estilo do tradutor e Munday (2008) do estilo da tradução e do estilo do tradutor, dando ênfase às conexões entre as escolhas estilísticas no nível microcontextual, de realizações linguísticas, e no nível macrocontextual, de ideologia e produção cultural.

Para Saldanha (2011, p.26) o conceito de estilo é muito vago e, com o objetivo de definir o estilo do tradutor, a autora afirma que a definição geral de estilo, como "um estilo X é a soma de traços linguísticos associados a textos ou amostras de textos definidos por um conjunto de parâmetros contextuais, Y" (citando LEECH 2008, p. 55) pode ser aplicada ao estilo de um texto traduzido, mas não ao estilo do tradutor. Para a pesquisadora, o estilo do tradutor não é a soma de traços linguísticos associados a textos traduzidos por um determinado tradutor. A autora utiliza o conceito de escrita autoral de Short (1996), que a define como uma forma de escrita que distingue um autor dentre outros, e o adapta para se referir ao estilo do tradutor, pois a característica principal de um estilo pessoal é a "proeminência" que é representada pelos padrões de escolhas consistentes e distintivos e um passo importante para a estilística tradutória é a identificação destes padrões.

Desse modo, Saldanha (2011, p. 30) apresenta sua concepção de estilo do tradutor como:

Uma 'forma de traduzir' que: é reconhecida em uma série de traduções feitas pelo mesmo tradutor, distingue o trabalho do tradutor do trabalho de outros, constitui um padrão de escolha coerente, é 'motivada', no sentido de que tem funções ou uma função visível, e não pode ser explicada puramente com referência ao estilo do autor ou do texto-fonte, ou como resultado de restrições linguísticas ${ }^{5}$ (SALDANHA, 2011, p.30).

5. No original " $A$ 'way of translating' which is felt to be recognizable across a range of translations by the same translator, distinguishes the translator's work from that of others, constitutes a coherent pattern of choice, is 'motivated', in the sense that it has a discernible function or functions, and cannot be explained purely with reference to the author or source-text style, or as the result of linguistic constraints." 


\section{A busca por padrões de colocações de itens lexicais}

Este estudo tem como principal motivação e fundamentação os resultados apontados em Stubbs $(2003,2005)$ sobre o estilo de HOD. Stubbs $(2003,2005)$ investiga como são desenvolvidos os temas principais na obra por meio do rastreamento de itens léxico-gramaticais. $\mathrm{O}$ autor destaca o uso frequente de formas flexionadas de $\mathrm{seem}^{*}$ e de palavras gramaticais como something, somebody, sometimes, somewhere, somehow e some para o desenvolvimento do tema de incerteza.

Para o autor, a recorrência de padrões de palavras e itens lexicais está relacionada com a proeminência motivada (Halliday, 1971). Baseado nos pressupostos de Sinclair $(1991,2004)$, Stubbs estuda os padrões linguísticos de fraseologia em HOD e a sua relação com os padrões da língua. Ele investiga as palavras mais recorrentes e analisa a fraseologia com duas palavras sequenciais, destacando os padrões léxico-gramaticais. $\mathrm{O}$ autor identifica como padrão mais frequente seemed to e compara os dados encontrados com um corpus de consulta, o BNC, descobrindo que o padrão seemed to é mais frequente em HOD que no corpus de textos ficcionais e escritos, caracterizando-se como padrão proeminente.

Stubbs (2005, p.14) sugere que a recorrência dos padrões fraseológicos encontrados contribui para a sensação de que o texto é muito repetitivo e que transmite a ideia dos temas principais do texto, tanto geográficos como psicológicos, concluindo que os dados quantitativos do corpus produzem novos olhares sobre o texto. O autor se baseia no conceito de item lexical de Sinclair (1991, 2004), como unidade mínima de sentido, em que uma palavra deve ser interpretada levando-se em consideração as relações que desenvolve com outras.

Sinclair (2004) defende o item lexical como unidade de sentido mínima e propõe que a análise seja feita em torno a esse item para verificar se há um padrão emergente. Para isso, ele conceitua os elementos que compõem seu modelo de análise e os divide em elementos obrigatórios e opcionais, sendo o núcleo (core), o coração do item lexical, um elemento obrigatório, e a colocação (collocation), frequente coocorrência de palavras que não têm um profundo efeito 
nos significados individuais das palavras, mas que apresenta um efeito sutil no significado total, um elemento opcional.

Este estudo também considerou alguns pressupostos de Biber et al. (2004), que apresenta os pacotes lexicais (lexical bundles), sequências de palavras mais frequentes em um registro, como um um construto linguístico único. Biber et al. (2004, p.371) explica que "os pacotes lexicais geralmente não são estruturas gramaticais completas ou idiomáticas, mas funcionam como blocos básicos construtores do discurso"6. Os autores identificam padrões de uso de agrupamentos lexicais por meio da construção de sua estrutura gramatical, os quais são classificados de acordo com sua função discursiva seguindo uma taxonomia funcional indutiva, isto é, os padrões são agrupados de acordo com a similaridade de suas funções discursivas, formando três agrupamentos principais, a saber: 1) expressões de opinião, 2) organizadores do discurso e 3) expressões referenciais. Neste trabalho, utilizou-se estes rótulos propostos por Biber et al. (2004) para descrever as funções discursivas das colocações encontradas neste estudo.

Considerando o propósito desta pesquisa, procurou-se identificar, então, traços do estilo individual de quatro tradutores e das traduções de HOD para o espanhol por meio da investigação da recorrência de padrões de colocações de itens lexicais formados a partir dos nódulos alg* e parec*, cujos equivalentes são apontados no TF (some*/any* e seem*) como proeminentes em Stubbs $(2003,2005)$. Neste estudo, priorizou-se a análise do elemento obrigatório de Sinclair (2004), o núcleo, e o elemento opcional, a colocação.

\section{Corpus e Metodologia}

O corpus de estudo é paralelo e composto pelo TF, Heart of Darkness, de Conrad (1902), e de quatro traduções do romance para o espanhol. Ele faz parte do Corpus de Estilo da Tradução - ESTRA(Magalhães, 2014). Heart of Darkness é considerada uma obra importante da literatura inglesa. Antes de sua publicação, em 1902, foi publicada como uma série de três episódios (1899) na Blackwood Magazine. É

6. No original "Lexical bundles are usually not complete gramatical structures nor are they idiomatic, but they function as basic building blocks of discourse." 
uma obra amplamente traduzida em várias línguas com, inclusive, muitas traduções em uma mesma língua, algumas vezes publicadas por editoras diferentes em um mesmo ano.

A história é, em sua quase totalidade, narrada em primeira pessoa pelo personagem Marlow, um inglês que obteve trabalho em uma companhia comercial como capitão de um barco a vapor para subir um rio africano (embora Conrad não identifique o rio). Sua tarefa é transportar marfim e encontrar Kurtz, um famoso comerciante de marfim. Marlow conta sua aventura a um grupo de amigos a bordo de um navio ancorado no Tâmisa. O romance possui dois narradores; o primeiro é um dos tripulantes do navio que introduz o personagem Marlow. Depois que Marlow é apresentado por esse narrador sem nome, ele conduz a maior parte da narrativa relatando sua viagem e como conheceu o Sr. Kurtz.

Stubbs (2005, p.2) divide a obra em 7 etapas narrativas e temas principais, que foram aqui traduzidos:

1. O livro começa com um narrador, não nomeado, em um barco no Tâmisa;

2. Marlow se torna o narrador e fala sobre o Tâmisa no período romano;

3. Marlow relata sua visita a uma cidade europeia;

4. Marlow conta a história que ocorre na maior parte do livro: ele viaja em um rio na África, em busca de um comerciante de marfim chamado Kurtz. Ele o encontra, mas Kurtz morre na viagem de volta, rio abaixo;

5. Marlow relata sua visita à noiva de Kurtz, quando já de volta à cidade europeia;

6 e 7. O livro termina com um parágrafo, do narrador inicial não nomeado, de volta no Tâmisa. A viagem de barco de Marlow se transforma em obsessão com Kurtz, um comerciante que se tornou um ladrão de marfim, roubando dos habitantes da região. Aparentemente, Kurtz ficou louco e era tratado como um "Deus" pela população nativa, ele tinha uma amante africana e parecia estar implicado em canibalismo. 
De acordo com Stubbs (2005, p.2) "os lugares na obra nunca são nomeados" ". Stubbs (2005) também afirma que existe uma forte tendência para repetidos contrastes, especialmente de palavras formadas pelos lemas light* e dark*, que remetem a um dos temas desenvolvidos na obra de Conrad. Além disso, em sua abordagem dos temas principais do romance, Stubbs (2005) aponta a alta frequência de palavras com sentido vago e de incerteza. Esse tema, conforme já mencionado, é investigado na presente pesquisa, do ponto de vista dos estudos de estilo da tradução baseados em corpus e, em parte, guiados pelo corpus.

O corpus de estudo é composto pelo original, Heart of Darkness, de Conrad e de quatro traduções do romance para o espanhol, totalizando 193.442 palavras. Todos os quatro TTs abordados neste estudo apresentam a mesma tradução do título: "El corazón de las tinieblas". Os nomes dos quatro tradutores dos textos em espanhol, bem como as informações sobre as editoras, ano e local de publicação, estão dispostos no Quadro 1, organizados por ordem cronológica:

Quadro 1 - Corpus de Estudo

\begin{tabular}{lllll}
\hline Obras & Autor/Tradutor & Editoras & Ano & Local \\
\hline Heart of Darkness & Joseph Conrad & Penguin Books & $\begin{array}{c}1902, \\
1994\end{array}$ & Londres, Inglaterra \\
& & & 2007 & Barcelona, Espanha \\
\hline $\begin{array}{l}\text { El corazón de las } \\
\text { tinieblas }\end{array}$ & Borja Folch & Ediciones B, S.A & & \\
\hline $\begin{array}{l}\text { El corazón de las } \\
\text { tinieblas }\end{array}$ & $\begin{array}{l}\text { Clara Iturero } \\
\text { Herrero }\end{array}$ & EDIMAT LIBROS, S.A & 2007 & Madri, Espanha \\
\hline $\begin{array}{l}\text { El corazón de las } \\
\text { tinieblas }\end{array}$ & $\begin{array}{l}\text { Amalia } \\
\text { Gieschen }\end{array}$ & Gárgola Ediciones & 2010 & $\begin{array}{l}\text { Buenos Aires, } \\
\text { Argentina }\end{array}$ \\
\hline $\begin{array}{l}\text { El corazón de las } \\
\text { tinieblas }\end{array}$ & Pablo Ingberg & Editorial Losada, S.A. & 2010 & $\begin{array}{l}\text { Buenos Aires, } \\
\text { Argentina }\end{array}$ \\
\hline
\end{tabular}

Fonte: Castro (2016).

Das quatro traduções, duas são traduções da Espanha, que foram publicadas no mesmo ano de 2007, sendo as outras duas da Argentina também publicadas no mesmo ano, em 2010. A Figura 1, a seguir, apresenta as capas destas publicações: 
Figura 1 - Capa das traduções por ordem cronológica de publicação

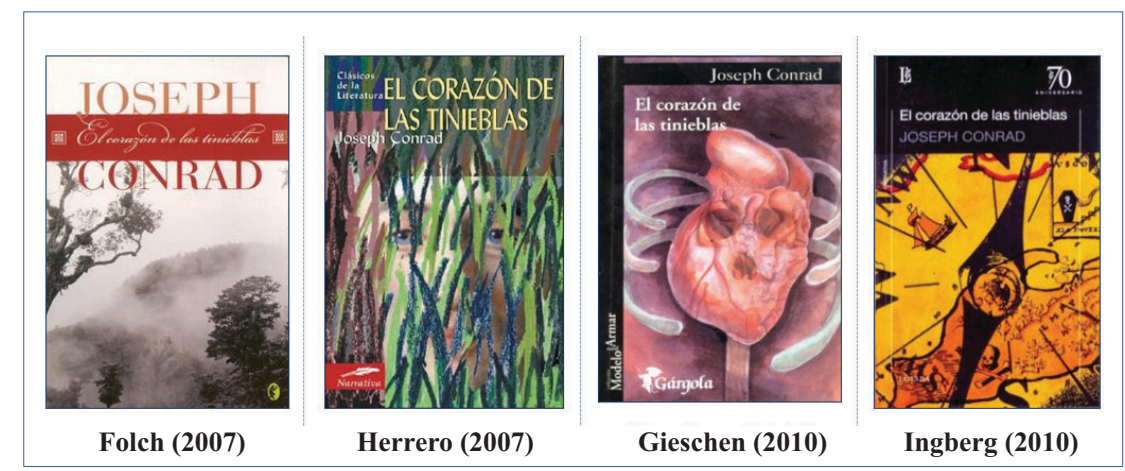

Fonte: Castro (2016).

O estudo foi quantitativo e qualitativo, sendo parcialmente baseado e parcialmente guiado pelo corpus, considerando que não é possível uma divisão estanque entre estas duas formas de análise. Desse modo, procedeu-se à investigação dos padrões com os nódulos de busca alg* e some*/any*, parec* e seem* e à identificação de mudanças observadas comparando-se as ocorrências desses padrões nos TTs e TF. Foram utilizadas as ferramentas do programa WordSmith Tools $@$ 6.0, especificamente a lista de palavras (word list), incluindo a aba lista de consistência detalhada (detailed consistency list) (cf. CASTRO, 2018) e o concordanciador (concord), incluindo as abas patterns e collocates.

Foram considerados apenas os quatro primeiros padrões mais frequentes de agrupamentos de palavras em torno dos nódulos (alg*, parec $^{*}$, some $^{*} /$ any $^{*}$ e seem $*$, os que se formaram a partir da primeira posição à direita $(\mathrm{R} 1)$ e à esquerda $(\mathrm{L} 1)$ do nódulo. Foram observadas, primariamente, formações de colocações com duas palavras, tomadas a partir da posição de R1 e da posição de L1, dependendo das colocações mais frequentes mostradas pela ferramenta. Porém, também foram considerados padrões de agrupamentos/colocações que se sobrepuseram formando agrupamentos maiores, de três palavras (L1 + nódulo + R1), sendo este o limite máximo de extensão do nódulo considerado nesta análise. 
Os padrões de colocações encontrados na análise foram comparados com dados de um corpus de consulta, para identificar padrões usuais ou não usuais. Para a análise das traduções utilizou-se o Corpus del Español ${ }^{8}$ e para o TF utilizou-se o BYU-BNC ${ }^{9}$ (British National Corpus), ambos com 100 milhões de palavras. Utilizaram-se o corpus geral e o corpus específico de ficção para a comparação das colocações. O tamanho do corpus de ficção do Corpus del Español é de 4.769.873 palavras e do corpus de ficção do BYU-BNC é de 15.909.312 palavras.

Para uma melhor apreciação dos resultados do corpus em análise em comparação com os corpora de consulta, foi feito o cálculo da frequência normalizada para cada mil palavras (Stubbs, 2003, 2005), ou seja, os números de frequência absoluta são divididos pelo número total de palavras do texto e multiplicados por 1.000. Assim, tem-se uma comparação mais equilibrada, pois os números de frequência absoluta não podem ser devidamente comparados se os textos analisados forem proporcionalmente muito diferentes. Depois, foi feito o cálculo percentual entre os padrões para a melhor visualização da utilização dos padrões em cada tradução.

A partir desses dados, foi possível fazer uma comparação do estilo dos TTs entre si e em relação ao TF. Exemplos de uso dos principais padrões de colocações com os nódulos estudados foram retirados das linhas de concordância para analisar o cotexto, ampliando o horizonte da análise ao redor do nódulo, para a verificação da estrutura léxicogramatical mais recorrente utilizada em cada padrão, bem como a função discursiva realizada por esses padrões. As funções discursivas foram descritas e identificadas com base em Biber et al. (1999, 2004). A seção seguinte mostra e discute os resultados.

8. Disponível em http://www.corpusdelespanol.org/x.asp. Acesso em 17/04/2016.

9. Disponível em http://corpus.byu.edu/bnc/. Acesso em 17/04/2016. 


\section{Padrões de colocações de itens lexicais com alg*}

A Tabela 1 mostra os padrões de colocações de itens lexicais com alg* em HOD_Folch.

Tabela 1 - Frequência absoluta e normalizada de colocações com $\operatorname{alg} *$ em HOD_Folch

\begin{tabular}{|c|c|c|c|c|c|}
\hline Fonte & $\begin{array}{l}\text { Número de } \\
\text { Itens }\end{array}$ & Padrão & $\begin{array}{l}\text { Número de } \\
\text { Ocorrências }\end{array}$ & $\begin{array}{c}\text { Frequência } \\
\text { normalizada } \\
\text { por } 1.000\end{array}$ & $\begin{array}{c}\text { Percentual de } \\
\text { ocorrências } \\
\text { entre padrões } \\
(\%)\end{array}$ \\
\hline \multirow{4}{*}{ HOD_Folch } & \multirow{4}{*}{38.408} & Algo que & 12 & 0,31 & 42,46 \\
\hline & & Alguna clase & 06 & 0,16 & 21,92 \\
\hline & & Alguna vez & 05 & 0,13 & 17,81 \\
\hline & & Algo así & 05 & 0,13 & 17,81 \\
\hline \multirow{4}{*}{$\begin{array}{c}\text { Corpus_Cons } \\
\text { (total) }\end{array}$} & \multirow{4}{*}{100.000 .000} & Algo que & 2.531 & 0,03 & 50,00 \\
\hline & & Alguna clase & 25 & 0,00 & 0,00 \\
\hline & & Alguna vez & 1.855 & 0,02 & 33,33 \\
\hline & & Algo así & 621 & 0,01 & 16,66 \\
\hline \multirow{4}{*}{$\begin{array}{l}\text { Corpus_Cons } \\
\text { (ficção) }\end{array}$} & \multirow{4}{*}{4.769 .873} & Algo que & 701 & 0,15 & 51,72 \\
\hline & & Alguna clase & 05 & 0,00 & 0,00 \\
\hline & & Alguna vez & 472 & 0,10 & 34,48 \\
\hline & & Algo así & 195 & 0,04 & 13,79 \\
\hline
\end{tabular}

Fonte: Castro (2016).

O padrão algo que é o mais recorrente em HOD_Folch, com $42,46 \%$ de ocorrências. Este padrão é também o mais recorrente no corpus de ficção, com $51,72 \%$. No entanto, o segundo padrão mais recorrente no TT, alguna clase, com 21,92\% das ocorrências, não possui expressividade nos corpora de consulta, tendo em vista os valores de frequência normalizada e percentuais $(0,00)$. Os padrões de colocações alguna vez e algo así ocorrem com a mesma frequência em HOD_Folch $(0,13)$ e o mesmo percentual de ocorrências, $17,81 \%$. No corpus geral alguna vez ocorre o dobro de vezes do padrão algo así. No de ficção, alguna vez possui 0,10 de frequência normalizada e algo así 0,04 .

O padrão algo que é o padrão mais usual no corpus de ficção, com frequência normalizada 0,15 , portanto, a única que se aproxima das frequências normalizadas apresentadas pelos padrões de colocações 
em HOD_Folch. Embora a frequência normalizada de algo que em HOD_Folch seja 0,31, um número maior do que no corpus de ficção, pode-se dizer que este é um padrão também recorrente no corpus de consulta.

O padrão alguna vez, com 0,10 de frequência normalizada no corpus de ficção é o segundo padrão mais usual neste corpus. Com isso, conclui-se que os padrões algo que e alguna vez são usuais no corpus de ficção, mas não são comuns no corpus geral. O padrão alguna clase é o segundo mais recorrente em HOD_Folch e não possui números expressivos de ocorrências nos corpora de consulta, sendo um padrão de preferência deste tradutor. Algo así, o quarto padrão mais frequente em HOD_Folch, não possui expressividade no corpus de consulta geral, tampouco no de ficção, com 0,01 e 0,04 de frequência normalizada respectivamente. Então, pode-se inferir que este também pode ser apontado como padrão de colocação de preferência deste tradutor.

Os resultados mostraram que Folch possui preferência por padrões cuja estrutura se forma a partir do nódulo $+\mathrm{R} 1$. Em relação à estrutura gramatical destes padrões observou-se o uso de pronome quantificador indefinido + pronome relativo; pronome quantificador indefinido + substantivo (para os segundo e terceiro padrões) e pronome quantificador indefinido + advérbio (cf. Nueva Gramática de La Lengua Española, Real Academia Española, 2010).

Seguindo a classificação de Biber et al (1999, 2004), em relação às funções discursivas dos agrupamentos lexicais, esses quatro padrões possuem função discursiva referencial, isto é, são agrupamentos lexicais referenciais indicadores de imprecisão. No Quadro 2 observam-se alguns exemplos do uso dessas colocações, extraídos da tradução de Folch em comparação com o TF. 
Quadro 2 - Exemplos de padrões de colocações com alg* de HOD_Folch

\begin{tabular}{|c|c|c|}
\hline $\mathbf{N}^{\mathbf{0}}$ & HOD_FOLCH & HOD_CONRAD \\
\hline 01 & $\begin{array}{l}{[\ldots] \text { y una creencia entregada a la }} \\
\text { idea: algo que ensalzar y ante lo } \\
\text { que someterse y ofrecer sacrifi- } \\
\text { cios... [...] }\end{array}$ & $\begin{array}{l}{[\ldots] \text { and an unselfish belief in the idea- }} \\
\text { something you can set up, and bow down } \\
\text { before, and offer a sacrifice to...' [...] }\end{array}$ \\
\hline 02 & $\begin{array}{l}\text { Habia gran cantidad de rojo, algo } \\
\text { que siempre es bueno, porque así } \\
\text { uno sabe que alli se está haciendo } \\
\text { algún trabajo de verdad, }[. . .]\end{array}$ & $\begin{array}{l}\text { There was a vast amount of red-good to } \\
\text { see at any time, because one knows that } \\
\text { some real work is done in there, }[. . .]\end{array}$ \\
\hline 03 & $\begin{array}{l}\text { Algo así como un emisario de la } \\
\text { luz, }[\ldots]\end{array}$ & Something like an emissary of light, $[\ldots]$ \\
\hline 04 & $\begin{array}{l}\text { “'Alguna vez había visto algo así, } \\
\text { eh? [...] }\end{array}$ & $\begin{array}{l}\text { 'Did you ever see anything like it }-e h \text { ? } \\
{[\ldots]}\end{array}$ \\
\hline
\end{tabular}

Fonte: Castro (2016).

No exemplo 1 o pronome relativo que foi obrigatoriamente adicionado pelo tradutor e no exemplo 2 a colocação algo que não é equivalente óbvio de outra no TF. Nos exemplos 3 e 4, para traduzir expressões como something like it e anything like it, Folch utiliza a colocação algo así, mantendo o clima de incerteza do TF. É importante ressaltar que o tradutor tinha a opção de tradução por algo como, usada pelos outros tradutores. A Tabela 2 mostra os padrões com alg* mais recorrentes em HOD_Herrero.

Tabela 2 - Frequência absoluta e normalizada de colocações com alg* em HOD_Herrero

\begin{tabular}{cccccc}
\hline Fonte & $\begin{array}{c}\text { Número de } \\
\text { Itens }\end{array}$ & Padrão & $\begin{array}{c}\text { Número de } \\
\text { Ocorrên- } \\
\text { cias }\end{array}$ & $\begin{array}{c}\text { Frequência } \\
\text { normalizada } \\
\text { por 1.000 }\end{array}$ & $\begin{array}{c}\text { Percentual de } \\
\text { ocorrências } \\
\text { entre padrões } \\
\text { (\%) }\end{array}$ \\
\hline \multirow{2}{*}{ HOD_Herrero } & 38.043 & De algún & 16 & 0,42 & 37,17 \\
& & Algo de & 08 & 0,21 & 25,66 \\
Corpus_Cons & Algo que & 08 & 0,29 & 18,58 \\
(total) & 100.000 .000 & De algún & 1486 & 0,01 & 18,58 \\
& & De alguna & 1701 & 0,02 & 12,50 \\
& & Algo de & 2.252 & 0,02 & 25,00 \\
& & Algo que & 2.531 & 0,03 & 25,00 \\
\hline
\end{tabular}




\begin{tabular}{cccccc}
\hline Fonte & $\begin{array}{c}\text { Número de } \\
\text { Itens }\end{array}$ & Padrão & $\begin{array}{c}\text { Número de } \\
\text { Ocorrên- } \\
\text { cias }\end{array}$ & $\begin{array}{c}\text { Frequência } \\
\text { normalizada } \\
\text { por 1.000 }\end{array}$ & $\begin{array}{c}\text { Percentual de } \\
\text { ocorrências } \\
\text { entre padrões } \\
\text { (\%) }\end{array}$ \\
\hline & & De algún & 351 & 0,07 & 19,44 \\
$\begin{array}{c}\text { Corpus_Cons } \\
\text { (ficçã̃o) }\end{array}$ & 4.769 .873 & De alguna & 302 & 0,06 & 16,66 \\
& & Algo de & 390 & 0,08 & 22,22 \\
& & Algo que & 701 & 0,15 & 41,66 \\
\hline
\end{tabular}

Fonte: Castro (2016).

Na Tabela 2, os dois primeiros padrões de colocações escolhidos por Herrero não são os mesmos de Folch, o que corrobora a hipótese de que haverá mudanças nos TTs em relação às preferências de colocações com itens lexicais escolhidos para a construção do tema de incerteza. HOD_Folch apresentou os quatro primeiros padrões de colocações mais frequentes formados pelo posicionamento de itens em R1. Em HOD_Herrero observa-se que os dois primeiros padrões de colocações mais frequentes foram formados a partir do posicionamento de itens em L1, à esquerda do nódulo, e os dois últimos foram formados a partir do posicionamento de itens em R1, sendo algo que o único padrão em comum com Folch.

O padrão de algún é o mais recorrente em HOD_Herrero, com $37,17 \%$ de ocorrências. Comparando a frequência dos padrões mais frequentes em HOD_Herrero, de algún $(0,42)$, de alguna $(0,29)$, algo de $(0,21)$ e algo que $(0,21)$, com a frequência destes padrões nos corpora de consulta verificou-se que os três primeiros padrões de Herrero não são recorrentes nos corpora de consulta, o que indica que são padrões de preferência desta tradutora. Porém, o padrão algo que, também observado em Folch, é recorrente no corpus de ficção apresentando 0,15 de frequência normalizada, o maior valor entre os valores dos corpora de consulta.

Quanto à estrutura gramatical destes padrões, tem-se o uso de preposição + pronome quantificador indefinido para os dois primeiros padrões; pronome quantificador indefinido + preposição para o terceiro e pronome quantificador indefinido + pronome relativo para o último. Observa-se um padrão de preferência pelo uso da preposição de tanto no posicionamento à esquerda como à direita do nódulo. 
Ampliando um pouco o horizonte de análise, considerando os posicionamentos $\mathrm{L} 1+$ nódulo $+\mathrm{R} 1$, viu-se que das 16 ocorrências da colocação de algún, 4 são ocorrências da expressão lexical de algún modo, para traduzir somehow ou some way do TF, o que faz com que a estrutura gramatical preposição + pronome quantificador indefinido seja parte de uma locução adverbial nestas frases. As outras 12 ocorrências de de algún são seguidas por um substantivo, mantendo a função de pronome indefinido da forma algún. Ampliou-se também o horizonte para as linhas com a colocação de alguna e viu-se que ocorreram 4 frases em que se formou a locução adverbial de alguna manera para traduzir somehow do TF. As colocações com itens lexicais com alg* em HOD Herrero também funcionaram como pacotes referenciais de imprecisão e, principalmente os três primeiros padrões, marcaram preferências lexicais dessa tradutora. O Quadro 3 ilustra essas preferências com exemplos destas colocações.

Quadro 3 - Exemplos de padrões de colocações com alg* de HOD_Herrero

\begin{tabular}{|c|c|c|}
\hline $\mathbf{N}^{\mathbf{o}}$ & HOD_HERRERO & HOD_CONRAD \\
\hline 01 & $\begin{array}{l}\text { Lo curioso era que aparen- } \\
\text { temente se habia olvidado } \\
\text { de todo lo de aquella valiosa } \\
\text { posdata, porque, más adelante, } \\
\text { cuando de alguna manera } \\
\text { volvió en sí, [...] }\end{array}$ & $\begin{array}{l}\text { The curious part was that he had } \\
\text { apparently forgotten all about that valuable } \\
\text { postscriptum, because, later on, when he in a } \\
\text { sense came to himself, [...] }\end{array}$ \\
\hline 02 & $\begin{array}{l}{[. . .] \text { como un pasaje a través }} \\
\text { de algún mundo inconcebible } \\
\text { en el que no hubiera ninguna } \\
\text { esperanza ni deseo. }\end{array}$ & $\begin{array}{l}{[\ldots] \text { like a passage through some }} \\
\text { inconceivable world that had no hope in it } \\
\text { and no desire. }\end{array}$ \\
\hline 03 & $\begin{array}{l}\text { Ya sabéis que no estoy } \\
\text { acostumbrando a tanta } \\
\text { ceremonia y habia algo de mal } \\
\text { agüero en el aire. }\end{array}$ & $\begin{array}{l}\text { You know I am not used to such ceremonies, } \\
\text { and there was something ominous in the } \\
\text { atmosphere. }\end{array}$ \\
\hline 04 & $\begin{array}{l}{[. . .] \text { era algo de lo que me da- }} \\
\text { ría cuenta unos meses después } \\
\text { y mil millas más lejos. }\end{array}$ & $\begin{array}{l}{[\ldots] \text { I was only to find out several months }} \\
\text { later and a thousand miles farther. }\end{array}$ \\
\hline
\end{tabular}

Fonte: Castro (2016).

No exemplo 1 a tradutora opta por uma colocação com uma palavra formada com alg* para traduzir in a sense do TF, reforçando assim o 
recurso de reiteração desses itens lexicais no TT. No exemplo 2 observase que a preposição de, aparentemente de uma colocação com algún, na realidade faz parte do pacote lexical a través de, equivalente óbvio do advérbio through do TF. Nos exemplos 3 e 4 a colocação algo de é provavelmente uma escolha individual dessa tradutora, uma vez que no exemplo 3 ela poderia ter seguido a estrutura do TF usando um adjetivo imediatamente após o pronome indefinido, e no exemplo 4 ela fez um acréscimo da colocação fazendo referência ao que foi dito antes. Na realidade o uso da preposição de na formação de colocações com alg* parece ser uma marca de Herrero, pois está presente em três dos quatro principais padrões. A Tabela 3 mostra os padrões de colocações em HOD Gieschen.

Tabela 3 - Frequência absoluta e normalizada de colocações com $\operatorname{alg}{ }^{*}$ em HOD_Gieschen

\begin{tabular}{|c|c|c|c|c|c|}
\hline Fonte & $\begin{array}{l}\text { Número de } \\
\text { Itens }\end{array}$ & Padrão & $\begin{array}{l}\text { Número de } \\
\text { Ocorrências }\end{array}$ & $\begin{array}{c}\text { Frequência } \\
\text { normalizada } \\
\text { por } 1.000\end{array}$ & $\begin{array}{c}\text { Percentual de } \\
\text { ocorrências } \\
\text { entre padrões } \\
(\%)\end{array}$ \\
\hline \multirow{4}{*}{ HOD_Gieschen } & \multirow{4}{*}{38.756} & De alguna & 15 & 0,39 & 32,77 \\
\hline & & De algún & 12 & 0,31 & 26,05 \\
\hline & & Algo que & 11 & 0,28 & 23,53 \\
\hline & & En algún & 08 & 0,21 & 17,65 \\
\hline \multirow{4}{*}{$\begin{array}{l}\text { Corpus_Cons } \\
\text { (total) }\end{array}$} & \multirow{4}{*}{100.000 .000} & De alguna & 1701 & 0,02 & 28,57 \\
\hline & & De algún & 1486 & 0,01 & 14,29 \\
\hline & & Algo que & 2.531 & 0,03 & 42,86 \\
\hline & & En algún & 962 & 0,01 & 14,29 \\
\hline \multirow{4}{*}{$\begin{array}{l}\text { Corpus_Cons } \\
\text { (ficção) }\end{array}$} & \multirow{4}{*}{4.769 .873} & De alguna & 302 & 0,06 & 17,65 \\
\hline & & De algún & 351 & 0,07 & 20,59 \\
\hline & & Algo que & 701 & 0,15 & 44,12 \\
\hline & & En algún & 301 & 0,06 & 17,65 \\
\hline
\end{tabular}

Fonte: Castro (2016).

HOD_Gieschen apresenta os três primeiros padrões de colocações iguais a trềs padrões apresentados em HOD_Herrero, sendo algo que comum também em Folch. Apenas en algún é diferente em relação à Herrero, e também não aparece em Folch. Os dois primeiros padrões em HOD_Gieschen são também os dois primeiros em HOD_Herrero, com pouca diferença na frequência. A maioria dos padrões encontrados em HOD_Gieschen não tem recorrência significativa nos corpora de 
consulta, visto que a diferença nos valores de frequência destes padrões é nítida na Tabela 3, com ressalva para o padrão algo que que, como visto nas análises dos tradutores anteriores, é um padrão comum no corpus de ficção.

Gieschen apresenta preferência pelo posicionamento de L1 + nódulo em três padrões e, apenas no terceiro, pelo posicionamento nódulo $+\mathrm{R} 1$. Para os três padrões apresenta estrutura gramatical de preposição + pronome quantificador indefinido; para o terceiro padrão opta por pronome quantificador indefinido + pronome relativo. $\mathrm{O}$ uso da preposição de também é uma marca observada na formação de colocações com alg* em HOD_Gieschen.

Os padrões mais frequentes em HOD_Gieschen funcionam como agrupamentos lexicais referenciais de imprecisão, exceto pelo último, que até este ponto da análise só aparece neste TT. Este agrupamento é um adjunto referencial de lugar, embora o uso do pronome indefinido em si constrói a ideia de imprecisão do TF. O Quadro 4 traz exemplos de Gieschen.

Quadro 4 - Exemplos de padrões de colocações com alg* de HOD_Gieschen

\begin{tabular}{|c|c|c|}
\hline $\mathbf{N}^{\mathbf{0}}$ & HOD_GIESCHEN & HOD_CONRAD \\
\hline 01 & $\begin{array}{l}\text { Pude deducir de a ratos que } \\
\text { se trataba de_algún hombre } \\
\text { que supuestamente estaba } \\
\text { en el distrito de Kurtz, y } \\
\text { cuya presencia el director } \\
\text { desaprobada. }\end{array}$ & $\begin{array}{l}\text { I gathered in snatches that this was some } \\
\text { man supposed to be in Kurtz's district, and } \\
\text { of whom the manager did not approve. }\end{array}$ \\
\hline 02 & $\begin{array}{l}\text { Un negro atlético, procedente } \\
\text { de alguna tribu de la costa, } \\
\text { y educado por mi desdichado } \\
\text { predecesor, era el timonel. }\end{array}$ & $\begin{array}{l}\text { An athletic black belonging to some coast } \\
\text { tribe and educated by my poor predecessor, } \\
\text { was the helmsman. }\end{array}$ \\
\hline 03 & $\begin{array}{l}\text { "También esa pregunta tiene } \\
\text { algo que ver con la ciencia?" }\end{array}$ & $\begin{array}{l}\text { "Is that question in the interests of science, } \\
\text { too?" }\end{array}$ \\
\hline 04 & $\begin{array}{l}\text { Mi propósito era vagar bajo } \\
\text { sus sombras por un momento; } \\
\text { pero en cuanto entré me pareció } \\
\text { que había penetrado en algún } \\
\text { tenebroso círculo del Inferno. }\end{array}$ & $\begin{array}{l}\text { My purpose was to stroll into the shade } \\
\text { for a moment; but no sooner within than it } \\
\text { seemed to me I had stepped into the gloomy } \\
\text { circle of some Inferno. }\end{array}$ \\
\hline
\end{tabular}

Fonte: Castro (2016). 
Nos exemplos 1 e 2 observou-se a inclusão da preposição de no TT em relação ao TF e, também, uma mudança na escolha de verbos, de was para tratar-se no exemplo 1, o que provocou uma mudança de estrutura na frase. No exemplo 3 a tradutora opta pela colocação algo que para um extrato do TF que não continha nenhum item lexical com some*/any*. No exemplo 4, no TF o pronome some tinha a função de determinante do substantivo Inferno e no TT algún faz referência a tenebroso círculo, mostrando uma mudança em relação à posição do uso do pronome indefinido em relação ao TF. A Tabela 4 a seguir traz os padrões de HOD_Ingberg.

Tabela 4 - Frequência absoluta e normalizada de colocações com $\operatorname{alg} *$ em HOD_Ingberg

\begin{tabular}{|c|c|c|c|c|c|}
\hline Fonte & $\begin{array}{l}\text { Número de } \\
\text { Itens }\end{array}$ & Padrão & $\begin{array}{l}\text { Número de } \\
\text { Ocorrências }\end{array}$ & $\begin{array}{c}\text { Frequência } \\
\text { normalizada } \\
\text { por } 1.000\end{array}$ & $\begin{array}{c}\text { Percentual de } \\
\text { ocorrências entre } \\
\text { padrões }(\%)\end{array}$ \\
\hline \multirow{4}{*}{ HOD_Ingberg } & \multirow{4}{*}{39.443} & Alguna vez & 12 & 0,30 & 28,04 \\
\hline & & De algún & 11 & 0,29 & 27,10 \\
\hline & & De alguna & 10 & 0,25 & 23,36 \\
\hline & & Algo que & 09 & 0,23 & 21,49 \\
\hline \multirow{4}{*}{$\begin{array}{l}\text { Corpus_Cons } \\
\text { (total) }\end{array}$} & \multirow{4}{*}{100.000 .000} & Alguna vez & 1.855 & 0,02 & 25,00 \\
\hline & & De algún & 1486 & 0,01 & 12,50 \\
\hline & & De alguna & 1701 & 0,02 & 25,00 \\
\hline & & Algo que & 2.531 & 0,03 & 37,50 \\
\hline \multirow{4}{*}{$\begin{array}{l}\text { Corpus_Cons } \\
\text { (ficção) }\end{array}$} & \multirow{4}{*}{4.769 .873} & Alguna vez & 472 & 0,10 & 26,32 \\
\hline & & De algún & 351 & 0,07 & 18,42 \\
\hline & & De alguna & 302 & 0,06 & 15,79 \\
\hline & & Algo que & 701 & 0,15 & 39,47 \\
\hline
\end{tabular}

Fonte: Castro (2016).

Em HOD_Ingberg o padrão mais frequente foi alguna vez $(0,30)$, que também é frequente em HOD_Folch. Dois padrões frequentes em Ingberg, de algún e de alguna, também foram apontados em HOD_Herrero e HOD_Gieschen. O padrão algo que aparece como frequente em todas as traduções.

Apenas o primeiro padrão, alguna vez, aparece com mais expressividade no corpus de ficção, com 0,10 de frequência normalizada, mas, se compararmos sua referência com aquela em HOD_Ingberg $(0,30)$, vê-se que este padrão ocorre três vezes mais no texto de Ing- 
berg, indicando assim sua preferência. Os padrões que mais ocorrem em HOD_Ingberg são mais recorrentes neste texto do que nos corpora de consulta.

Os segundo e terceiro padrões em HOD_Ingberg apresentam estrutura gramatical preposição + pronome quantificador indefinido, com o uso preferencial da preposição de. O primeiro padrão é constituído por pronome quantificador indefinido + substantivo e o último pronome quantificador indefinido + pronome relativo. Esses padrões funcionam como colocações referenciais de imprecisão. O Quadro 5 mostra exemplos dessas colocações.

Quadro 5 - Exemplos de padrões de colocações com alg* em HOD_Ingberg

\begin{tabular}{|c|c|c|}
\hline $\mathbf{N}^{\mathbf{0}}$ & HOD_INGBERG & HOD_CONRAD \\
\hline 01 & $\begin{array}{l}\text { Cuán insidioso podía ser, } \\
\text { además, es algo que yo sólo iba a } \\
\text { descubrir varios meses más tarde } \\
\text { y mil millas más lejos. }\end{array}$ & $\begin{array}{l}\text { How insidious he could be, too, I was } \\
\text { only to find out several months later and a } \\
\text { thousand miles farther. }\end{array}$ \\
\hline 02 & $\begin{array}{l}{[. . .] \text { (eran treinta contra cinco) }} \\
\text { y se dieron un buen atracón por } \\
\text { una vez es algo que todavía me } \\
\text { asombra cuando pienso en eso. }\end{array}$ & $\begin{array}{l}{[\ldots] \text { - they were thirty to five-and have }} \\
\text { a good tuck-in for once, amazes me now } \\
\text { when I think of it. }\end{array}$ \\
\hline 03 & $\begin{array}{l}\text { Decian que había causado el } \\
\text { fuego de algún modo; sea como } \\
\text { fuera, chillaba horriblemente. }\end{array}$ & $\begin{array}{l}\text { They said he had caused the fire in some } \\
\text { way; be that as it may, he was screeching } \\
\text { most horribly. }\end{array}$ \\
\hline 04 & $\begin{array}{l}\text { Había sido en vida un timonel de } \\
\text { segunda linea, pero ahora que } \\
\text { estaba muerto podría haberse } \\
\text { convertido en una tentación de } \\
\text { primera clase y probable causa } \\
\text { de algún problema sorprendente. }\end{array}$ & $\begin{array}{l}\text { He had been a very second-rate helmsman } \\
\text { while alive, but now he was dead he might } \\
\text { have become a first-class temptation, and } \\
\text { possibly cause some startling trouble. }\end{array}$ \\
\hline
\end{tabular}

Fonte: Castro (2016).

No exemplo 1 incluiu-se a colocação algo que em uma oração em que não ocorriam palavras formadas com some* ou any* no TF. O mesmo acontece no exemplo 2, em ambos os casos algo que está fazendo referência ao que foi dito antes na oração, marcando assim sua função referencial. No exemplo 3 o tradutor optou pela preposição de para a tradução de in do TF, e no exemplo 4 houve a inclusão da preposição de fazendo com que o complemento verbal (objeto direto) 
se transforme em complemento nominal preposicionado, uma vez que no TF trata-se de um verbo (cause) que no TT transformou-se em substantivo, causa.

Comparando os resultados dos padrões de colocações das quatro traduções analisadas observou-se que HOD_Herrero e HOD_Gieschen apresentaram algumas escolhas de padrões e números de frequência normalizada mais próximos entre si. HOD_Folch e HOD_Ingberg apresentaram dois padrões que são comuns no corpus de ficção, alguna vez e algo que. No entanto, de uma forma geral, todos os padrões de colocações dos quatro TTs foram mais recorrentes nas traduções que nos corpora de consulta.

Em HOD_Folch verificaram-se dois padrões distintos, alguna clase e algo así. Herrero apresenta o padrão algo de, que não aparece em nenhum outro TT, e Gieschen possui um padrão individual, en algún. Enquanto Folch segue sendo o tradutor que mais apresenta variedade nos padrões de colocações de itens lexicais com alg*, Ingberg não apresenta nenhuma escolha individual diferente dos demais tradutores.

Todavia, é necessária a comparação destes padrões com os padrões de colocações de itens lexicais com some*/any* do TF, para que se considerar os primeiros como preferências individuais dos tradutores. Apresentam-se as Tabelas 5 e 6 com os padrões de colocações de itens lexicais com some* e any*, respectivamente, em HOD_Conrad.

Tabela 5 - Frequência absoluta e normalizada de colocações com some* em HOD Conrad

\begin{tabular}{cccccc}
\hline Fonte & $\begin{array}{c}\text { Número de } \\
\text { Itens }\end{array}$ & Padrão & $\begin{array}{c}\text { Número de } \\
\text { Ocorrências }\end{array}$ & $\begin{array}{c}\text { Frequência } \\
\text { normalizada } \\
\text { por 1.000 }\end{array}$ & $\begin{array}{c}\text { Percentual de } \\
\text { ocorrências entre } \\
\text { padrões (\%) }\end{array}$ \\
\hline \multirow{2}{*}{ HOD_Conrad } & \multirow{2}{*}{38.792} & To some & 06 & 0,44 & 50,57 \\
& & At some & 06 & 0,15 & 17,24 \\
& & In some & 05 & 0,15 & 17,24 \\
\hline \multirow{2}{*}{$\begin{array}{c}\text { Corpus_Cons } \\
\text { (total) }\end{array}$} & \multirow{2}{*}{100.000 .000} & Of some & 7166 & 0,13 & 14,94 \\
\hline & & To some & 5195 & 0,05 & 25,92 \\
& & At some & 2624 & 0,03 & 18,52 \\
& In some & 12151 & 0,12 & 11,11 \\
\hline
\end{tabular}




\begin{tabular}{cccccc}
\hline Fonte & $\begin{array}{c}\text { Número de } \\
\text { Itens }\end{array}$ & Padrão & $\begin{array}{c}\text { Número de } \\
\text { Ocorrências }\end{array}$ & $\begin{array}{c}\text { Frequência } \\
\text { normalizada } \\
\text { por 1.000 }\end{array}$ & $\begin{array}{c}\text { Percentual de } \\
\text { ocorrências entre } \\
\text { padrões (\%) }\end{array}$ \\
\hline & & Of some & 929 & 0,06 & 30,00 \\
$\begin{array}{c}\text { Corpus_Cons } \\
\text { (ficção) }\end{array}$ & 15.909 .312 & To some & 563 & 0,04 & 20,00 \\
& & At some & 397 & 0,02 & 10,00 \\
& In some & 1237 & 0,08 & 40,00 \\
\hline
\end{tabular}

Fonte: Castro (2016).

$\mathrm{Na}$ Tabela 5 todos os padrões apresentaram número de frequência normalizada maior no TF do que nos corpora de consulta. Esses dados confirmam a hipótese de Stubbs $(2003,2005)$ de que Conrad escolheu palavras/itens lexicais e utilizou o recurso de reiteração para enfatizar o clima de mistério e dúvida na obra. Os primeiros padrões de colocações de itens lexicais com some* seguem o posicionamento L1 + nódulo, com estrutura gramatical preposição + pronome indefinido.

O padrão de colocação que mais ocorre no TF é of some $(0,44)$, os outros mais recorrentes são to some, at some e in some. O padrão in some apresentou frequência normalizada 0,12 no corpus de consulta geral, sendo o único padrão a se destacar no corpus de uso geral, mesmo assim não ultrapassa o valor normalizado do TF.

Ao compararmos os achados do TF com os dos TTs veremos que o primeiro padrão of some tem como equivalentes óbvios os padrões de algún e de alguna, ambos presentes nos TTs de Herrero, Gieschen e Ingberg, afastando a hipótese de que são usos preferenciais e individuais destes tradutores. Os padrões at some e in some do TF foram observados em Gieschen por meio do padrão en algún. No entanto, esta foi a única tradutora a utilizá-lo.

É necessário visualizar os padrões de colocações de itens lexicais com any* para se ter certeza de quais padrões são equivalentes óbvios de padrões do TF e quais são usos individuais do tradutor. A Tabela 6 apresenta a frequência de colocações de itens lexicais com any* em HOD_Conrad. 
Tabela 6 - Frequência absoluta e normalizada de colocações com any* em HOD_Conrad

\begin{tabular}{|c|c|c|c|c|c|}
\hline Fonte & $\begin{array}{l}\text { Número de } \\
\text { Itens }\end{array}$ & Padrão & $\begin{array}{l}\text { Número de } \\
\text { Ocorrências }\end{array}$ & $\begin{array}{c}\text { Frequência } \\
\text { normalizada } \\
\text { por } 1.000 \\
\end{array}$ & $\begin{array}{c}\text { Percentual de } \\
\text { ocorrências en- } \\
\text { tre padrões }(\%)\end{array}$ \\
\hline \multirow{4}{*}{ HOD_Conrad } & \multirow{4}{*}{38.792} & Of any & 05 & 0,13 & 31,71 \\
\hline & & For any & 04 & 0,10 & 24,39 \\
\hline & & Any kind & 04 & 0,10 & 24,39 \\
\hline & & Had any & 03 & 0,08 & 19,51 \\
\hline \multirow{4}{*}{$\begin{array}{l}\text { Corpus_Cons } \\
\text { (total) }\end{array}$} & \multirow{4}{*}{100.000 .000} & Of any & 9873 & 0,10 & 50,00 \\
\hline & & For any & 4115 & 0,04 & 20,00 \\
\hline & & Any kind & 5436 & 0,05 & 25,00 \\
\hline & & Had any & 1347 & 0,01 & 5,00 \\
\hline \multirow{4}{*}{$\begin{array}{l}\text { Corpus_Cons } \\
\text { (ficção) }\end{array}$} & \multirow{4}{*}{15.909 .312} & Of any & 844 & 0,05 & 22,73 \\
\hline & & For any & 462 & 0,03 & 13,64 \\
\hline & & Any kind & 1912 & 0,12 & 54,54 \\
\hline & & Had any & 387 & 0,02 & 9,09 \\
\hline
\end{tabular}

Fonte: Castro (2016).

Comparando-se as colocações de itens lexicais com some* com as colocações de itens lexicais com any*, verifica-se que Conrad utilizou mais colocações de itens com some*. O primeiro padrão com any* mais utilizado por Conrad é of any, $(0,13)$, que se somado à frequência normalizada de of some tem-se 0,57 , isto é, um número correspondente aproximado se somarmos as frequências normalizadas do padrão de algún e de alguna nos TTs que apresentam esse padrão. O padrão de colocação of any também possui uma frequência normalizada aproximada com a de Conrad no corpus geral, 0,10 , o que permite inferir que de todos os padrões escolhidos por Conrad este é o único comum no corpus geral. Conrad apresentou preferência por padrões com a formação a partir do posicionamento de L1 + nódulo, e apenas um padrão, any kind, com formação de nódulo + R1.

É interessante observar que estes são pacotes referenciais de imprecisão, bem como os padrões de colocações de itens lexicais com some*, mostrados na Tabela 5. O último padrão visto em Conrad é $\mathrm{Had}$ any, com baixa frequência $(0,08)$, se comparado aos outros padrões de itens lexicais com some* e any* examinados. Pode-se dizer que o autor preferiu usar padrões de colocações de itens lexicais com some* ao invés de padrões com any* para reforçar o tema de incerteza. No caso deste último padrão, a estrutura gramatical é diferente de todas 
aquelas observadas nos demais padrões, ou seja, ela é composta de verbo + pronome indefinido.

Comparando-se os padrões de colocações de HOD_Conrad com os padrões dos TTs analisados, observou-se que HOD_Folch foi a tradução que apresentou padrões mais diferenciados em relação ao TF e aos TTs entre si. Além disso, Folch foi também o tradutor que se diferenciou na escolha por padrões com formação a partir do posicionamento nódulo $+\mathrm{R} 1$, diferente dos padrões do $\mathrm{TF}$ e da maioria dos padrões dos outros TTs.

Verificou-se o uso de algo que em todos os TTs, cujo equivalente óbvio não aparece como padrão mais recorrente no TF. Este resultado permite inferir que pode se tratar de uma escolha obrigatória no espanhol, uma vez que no inglês o uso do that é opcional. As traduções de Herrero, Gieschen e Ingberg apresentaram escolhas por padrões de colocações que são equivalentes óbvios de padrões em HOD_Conrad, como de algún e de alguna, traduções para of some e of any, os padrões mais frequentes em HOD_Conrad.

De uma forma geral, as traduções de Herrero, Gieschen e Ingberg parecem apresentar equivalentes óbvios no espanhol para as escolhas de Conrad. Por sua vez, HOD_Folch opta por escolhas diferentes daquelas de Conrad e dos demais TTs. Tem-se um padrão em comum entre Folch e Ingberg, alguna vez, sendo o padrão mais recorrente em HOD_Ingberg $(0,30)$ e o terceiro mais recorrente em HOD_Folch $(0,13)$. Na próxima seção apresentam-se os resultados relativos à frequência das colocações com parec* nos TTs e com seem* no TF.

\section{Padrões de colocações de itens lexicais com parec*}

A Tabela 7 mostra os padrões de colocações de itens com parec* mais recorrentes em HOD_Folch. 
Tabela 7 - Frequência absoluta e normalizada de colocações com parec* em HOD_Folch

\begin{tabular}{|c|c|c|c|c|c|}
\hline Fonte & $\begin{array}{l}\text { Número de } \\
\text { Itens }\end{array}$ & Padrão & $\begin{array}{l}\text { Número de } \\
\text { Ocorrências }\end{array}$ & $\begin{array}{c}\text { Frequência } \\
\text { normalizada } \\
\text { por } 1.000\end{array}$ & $\begin{array}{c}\text { Percentual de } \\
\text { ocorrências } \\
\text { entre padrões } \\
(\%)\end{array}$ \\
\hline \multirow{4}{*}{ HOD_Folch } & \multirow{4}{*}{38.408} & Que parecía & 11 & 0,29 & 32,58 \\
\hline & & Al parecer & 10 & 0,26 & 29,21 \\
\hline & & Me parece & 07 & 0,18 & 20,22 \\
\hline & & Me pareció & 06 & 0,16 & 17,98 \\
\hline \multirow{4}{*}{$\begin{array}{l}\text { Corpus_Cons } \\
\quad \text { (total) }\end{array}$} & \multirow{4}{*}{100.000 .000} & Que parecía & 1.263 & 0,01 & 16,66 \\
\hline & & Al parecer & 1.356 & 0,01 & 16,66 \\
\hline & & Me parece & 4.172 & 0,04 & 66,66 \\
\hline & & Me pareció & 665 & 0,00 & 0,00 \\
\hline \multirow{4}{*}{$\begin{array}{l}\text { Corpus_Cons } \\
\text { (ficção) }\end{array}$} & \multirow{4}{*}{4.769 .873} & Que parecía & 328 & 0,07 & 12,28 \\
\hline & & Al parecer & 141 & 0,03 & 5,26 \\
\hline & & Me parece & 2.048 & 0,43 & 75,44 \\
\hline & & Me pareció & 214 & 0,04 & 7,02 \\
\hline
\end{tabular}

Fonte: Castro (2016).

Na Tabela 7 os padrões de colocações que parecía, al parecer e me pareció em HOD_Folch possuem frequência superior aos corpora de consulta. Pode-se inferir que esses padrões não são usuais nos corpora de consulta. No entanto, também é possível notar que eles são mais comuns no corpus de ficção do que no corpus total.

O padrão me parece apresenta frequência normalizada bem elevada no corpus ficcional, maior do que aquela do TT de Folch. Me parece é o terceiro padrão mais recorrente em HOD_Folch, porém o mais recorrente no corpus de ficção, com a frequência normalizada de 0,43 , sendo 0,19 em HOD_Folch. Com isso, conclui-se que este é o único padrão de colocação com parec* com frequência maior no corpus de consulta em relação ao texto analisado.

Os padrões de mais frequência em HOD_Folch são que parecía $(0,29)$ e al parecer $(0,26)$. No corpus de ficção observa-se que o padrão que mais ocorre é que parecía $(0,07)$. Todavia, a frequência deste padrão não se aproxima de me parece, o que é relevante já que na tradução que parecía é o padrão mais recorrente, o que ressalta a escolha na tradução, visto que é uma colocação menos usual nos corpora de consulta. O segundo padrão mais recorrente em HOD_Folch é al parecer, sendo o padrão que menos ocorre no corpus de ficção. 
Pesquisou-se novamente o corpus de consulta para checar em quais dos corpora existentes o padrão al parecer aparecia mais e verificou-se que se trata de um padrão usual em textos jornalísticos.

Os quatro primeiros padrões de colocações de Folch seguem o posicionamento de $\mathrm{L} 1+$ nódulo. A estrutura gramatical observada nos padrões de colocações de itens com parec* é pronome relativo + verbo, pronome pessoal + verbo (em dois padrões) e advérbio.

Segundo Biber et al (1999: 439) seem é um verbo cópula que tanto exerce a função referencial de caracterizar ou identificar o sujeito, quando acompanhado de frase nominal, como a função referencial de descrever um atributo do sujeito, quando seguido por uma frase preposicionada. Segundo os autores, quando combinado com complementos adjetivais seem marca opiniões pessoais com graus de surpresa e imprecisão.

Para apontarmos as funções discursivas dos quatro primeiros padrões de colocações de itens lexicais com parec* em HOD_Folch é necessário analisarmos o contexto do nódulo, ou seja, o complemento do verbo, seu predicativo do sujeito, pois ora poderá se tratar de uma colocação com função referencial de caracterização, identificação ou descrição, ora poderá se tratar de uma opinião epistêmica pessoal. Em ambos os casos, pode indicar graus de surpresa ou imprecisão. $\mathrm{O}$ Quadro 6 apresenta exemplos de colocações em HOD_Folch.

Quadro 6 - Exemplos de padrões de colocações com parec* em HOD_Folch

\begin{tabular}{|c|c|c|}
\hline $\mathbf{N}^{\mathbf{0}}$ & HOD_FOLCH & HOD_CONRAD \\
\hline 01 & $\begin{array}{l}{[\ldots] \text { desembarcábamos funcionarios }} \\
\text { de aduana para que recaudaran } \\
\text { impuestos en lo que parecía un } \\
\text { páramo dejado de la mano de Dios, } \\
{[\ldots]}\end{array}$ & $\begin{array}{l}{[\ldots] \text { landed custom-house clerks to levy }} \\
\text { toll in what looked like a God-forsaken } \\
\text { wilderness, }[\ldots]\end{array}$ \\
\hline 02 & $\begin{array}{l}\text { Aun así, tenía curiosidad por ver si } \\
\text { ese hombre que al parecer poseía } \\
\text { alguna suerte de bagaje moral [...] }\end{array}$ & $\begin{array}{l}\text { Still, I was curious to see whether this } \\
\text { man, who had come out equipped with } \\
\text { moral ideas of some sort, }[. . .]\end{array}$ \\
\hline 03 & $\begin{array}{l}\text { Estoy dispuesta a hacer lo que sea, } \\
\text { cualquier cosa por ti. Me parece } \\
\text { una idea espléndida. }\end{array}$ & $\begin{array}{l}\text { I am ready to do anything, anything for } \\
\text { you. It is a glorious idea. }\end{array}$ \\
\hline 04 & $\begin{array}{l}\text { Un trabajo elocuente, de hecho } \\
\text { bullia de elocuencia, pero con } \\
\text { demasiada tensión, me parece. }\end{array}$ & $\begin{array}{l}\text { It was eloquent, vibrating with } \\
\text { eloquence, but too high-strung, I think. }\end{array}$ \\
\hline
\end{tabular}


No exemplo 1 a colocação que parecía é acompanhada por uma frase nominal, un páramo dejado de la mano de Dios, o que confirma a função referencial de caracterização do sujeito, em que constrói a imprecisão com a escolha de parecía, no TF reforçada pela combinação de looked like com wilderness. No exemplo 2 vê-se a inclusão da colocação al parecer para a tradução de uma frase do TF onde não havia elementos de mistério e incerteza. $\mathrm{O}$ tradutor optou por uma frase adverbial modalizadora, cujo núcleo é um item lexical com o nódulo parec* $^{*}$ Vale ressaltar que a escolha por esse padrão é mais frequente em textos jornalísticos no corpus geral de consulta.

No exemplo 3 o tradutor escolhe me parece, que denota imprecisão, como equivalente de it is, uma afirmativa categórica simples com a função de caracterização. No exemplo 4 observa-se que a expressão me parece desempenha a função de opinião epistêmica pessoal, característica também observada nos outros três tradutores para a tradução de verbos de atitude pessoal como think e believe, por exemplo.

Pode-se inferir que Folch pode ter também uma preferência por padrões de colocações de textos jornalísticos, como al parecer, mas que também utiliza expressões de alta frequência em textos ficcionais, uma vez que é um tradutor profissional principalmente de textos ficcionais. Para uma afirmação mais concreta para esse resultado, faz-se necessária uma investigação do estilo desse tradutor, tanto por meio da comparação das escolhas de Borja Folch e dos outros tradutores de HOD como comparando textos autorais e traduções feitas por ele. Devido às delimitações do escopo desta pesquisa, verificou-se se esta é ou não uma tendência de Folch por meio da comparação das escolhas entre os tradutores estudados. A Tabela 8 traz os padrões de colocações em HOD_Herrero. 
Tabela 8 - Frequência absoluta e normalizada de colocações com parec* em HOD_Herrero

\begin{tabular}{|c|c|c|c|c|c|}
\hline Fonte & $\begin{array}{l}\text { Número de } \\
\text { Itens }\end{array}$ & Padrão & $\begin{array}{l}\text { Número de } \\
\text { Ocorrências }\end{array}$ & $\begin{array}{c}\text { Frequência } \\
\text { normalizada } \\
\text { por } 1.000\end{array}$ & $\begin{array}{c}\text { Percentual de } \\
\text { ocorrências } \\
\text { entre padrões } \\
(\%)\end{array}$ \\
\hline \multirow{4}{*}{ HOD_Herrero } & \multirow{4}{*}{38.043} & Que parecía & 14 & 0,37 & 44,05 \\
\hline & & Parecía que & 08 & 0,21 & 25,00 \\
\hline & & Que parecian & 05 & 0,13 & 15,48 \\
\hline & & No parecía & 05 & 0,13 & 15,48 \\
\hline \multirow{4}{*}{$\begin{array}{l}\text { Corpus_Cons } \\
\text { (total) }\end{array}$} & \multirow{4}{*}{100.000 .000} & Que parecía & 1.263 & 0,01 & 50,00 \\
\hline & & Parecía que & 728 & 0,01 & 50,00 \\
\hline & & Que parecían & 446 & 0,00 & 0,00 \\
\hline & & No parecía & 337 & 0,00 & 0,00 \\
\hline \multirow{4}{*}{$\begin{array}{l}\text { Corpus_Cons } \\
\text { (ficção) }\end{array}$} & \multirow{4}{*}{4.769 .873} & Que parecía & 328 & 0,07 & 43,75 \\
\hline & & Parecía que & 183 & 0,04 & 25,00 \\
\hline & & Que parecian & 124 & 0,03 & 18,75 \\
\hline & & No parecía & 88 & 0,02 & 12,5 \\
\hline
\end{tabular}

Fonte: Castro (2016).

De uma forma geral, todas as ocorrências dos padrões verificados são maiores em HOD_Herrero do que no Corpus del Español. O primeiro padrão encontrado foi o mesmo encontrado em HOD_Folch, que parecía $(0,37)$.

Parecía que é o segundo padrão mais proeminente em HOD_Herrero com frequência de 0,21 , muito maior do que os corpora de consulta analisados. Os dois últimos padrões observados em HOD_Herrero são que parecían e no parecía, com a mesma frequência normalizada, 0,13 . Observa-se que estes dois padrões não possuem expressividade no corpus geral $(0,00)$, e baixa expressividade no corpus de ficção, com 0,03 e 0,02 respectivamente.

Herrero apresentou três padrões que seguiram o posicionamento de L1 + nódulo, assim como Folch, e um padrão de colocação com o posicionamento contrário, nódulo $+\mathrm{R} 1$. Herrero usou a estrutura gramatical pronome relativo + verbo em dois padrões e verbo + pronome relativo em um, e no último padrão apresentou a estrutura advérbio de negação + verbo, diferenciando-se assim de Folch em suas escolhas. A tradutora apresenta em três padrões a combinação com pronome relativo que. Herrero também teve comportamento similar em relação ao uso da preposição de nos três primeiros padrões de colocações de 
itens lexicais com alg*, o que confirma sua baixa variedade lexical em relação a Folch, por exemplo.

Em relação à função discursiva, sabe-se que estes padrões desempenham, em sua maioria, funções referenciais de caracterização, descrição e identificação do sujeito, por se tratarem de usos com verbo cópula, mas que também desempenham opiniões epistêmicas pessoais, dependendo dos complementos verbais. Todas essas funções denotam imprecisão e surpresa. No Quadro 7 são apresentados alguns exemplos de colocações em HOD_Herrero.

Quadro 7 - Exemplos de padrões de colocações com parec* em HOD_Herrero

\begin{tabular}{c|l|l}
\hline $\mathbf{N}^{\mathbf{0}}$ & \multicolumn{1}{|c|}{ HOD_HERRERO } & \multicolumn{1}{c}{ HOD_CONRAD } \\
\hline $\mathbf{0 1}$ & $\begin{array}{l}\text { El borde de una jungla colosal, de } \\
\text { un verde tan oscuro que parecía } \\
\text { casi negro, }[. . .]\end{array}$ & $\begin{array}{l}\text { The edge of a colossal jungle, so dark- } \\
\text { green as_to be almost black, }[. . .]\end{array}$ \\
\hline $\mathbf{0 2}$ & $\begin{array}{l}\text { Los largos tramos, que parecían } \\
\text { todos el mismo, }[. . .]\end{array}$ & $\begin{array}{l}\text { The long reaches that were like one and } \\
\text { the same reach, }[. . .]\end{array}$ \\
\hline $\mathbf{0 3}$ & $\begin{array}{l}\text { I...I parecía que se vislumbraba } \\
\text { algo, pero ya estaba sellada. }\end{array}$ & $\begin{array}{l}\text { You fancied you had seen things - but the } \\
\text { seal was on. }\end{array}$ \\
\hline $\mathbf{0 4}$ & La tierra no parecía terrenal. & 'The earth seemed unearthly. \\
\hline
\end{tabular}

Fonte: Castro (2016).

Nos exemplos 1 e 4 que parecía e no parecía desempenham uma função referencial de descrição do sujeito, com expressão de opinião imprecisa, uma vez que são seguidas por complementos adjetivais. Os exemplos 2 e 3 , seguidos de orações adjetivais ou nominais, respectivamente, caracterizam e identificam o sujeito, também com certo grau de imprecisão.

Pode-se inferir que Herrero apresenta preferências por padrões pouco usuais nos corpora de consulta analisados, que podem ter sido escolhidos deliberadamente. É também relevante apontar que, embora o primeiro padrão mais recorrente seja o mesmo encontrado em HOD_Folch, essa tradução apresentou outros padrões recorrentes que não apareceram no primeiro TT investigado, parecía que, que parecían e no parecía, dois deles (exemplos 1 e 3 ) como escolha de equivalen- 
tes menos óbvios para as to be e You fancied. A Tabela 9 apresenta os padrões de HOD_Gieschen.

Tabela 9 - Frequência absoluta e normalizada de colocações com parec* em HOD_Gieschen

\begin{tabular}{|c|c|c|c|c|c|}
\hline Fonte & $\begin{array}{l}\text { Número de } \\
\text { Itens }\end{array}$ & Padrão & $\begin{array}{l}\text { Número de } \\
\text { Ocorrências }\end{array}$ & $\begin{array}{c}\text { Frequência } \\
\text { normalizada } \\
\text { por } 1.000\end{array}$ & $\begin{array}{c}\text { Percentual de } \\
\text { ocorrências } \\
\text { entre padrões } \\
(\%)\end{array}$ \\
\hline \multirow{4}{*}{$\begin{array}{c}\text { HOD_- } \\
\text { Gieschen }\end{array}$} & \multirow{4}{*}{38.756} & Que parecia & 15 & 0,39 & 35,13 \\
\hline & & Me pareció & 11 & 0,28 & 25,23 \\
\hline & & Parecía que & 09 & 0,23 & 20,72 \\
\hline & & No parecía & 08 & 0,21 & 18,92 \\
\hline \multirow{4}{*}{$\begin{array}{c}\text { Corpus_Cons } \\
\text { (total) }\end{array}$} & \multirow{4}{*}{100.000 .000} & Que parecía & 1.263 & 0,01 & 33,33 \\
\hline & & Me pareció & 665 & 0,01 & 33,33 \\
\hline & & Parecía que & 728 & 0,01 & 33,33 \\
\hline & & No parecía & 337 & 0,00 & 0,00 \\
\hline \multirow{4}{*}{$\begin{array}{l}\text { Corpus_Cons } \\
\text { (ficção) }\end{array}$} & \multirow{4}{*}{4.769 .873} & Que parecía & 328 & 0,07 & 41,18 \\
\hline & & Me pareció & 214 & 0,04 & 23,53 \\
\hline & & Parecía que & 183 & 0,04 & 23,53 \\
\hline & & No parecía & 88 & 0,02 & 11,76 \\
\hline
\end{tabular}

Fonte: Castro (2016).

Na Tabela 9 os padrões mais frequentes em HOD_Gieschen foram que parecía $(0,39)$, me pareció $(0,28)$, parecía que $(0,23)$ e no parecía $(0,21)$. A frequência normalizada de todos estes padrões é maior na tradução de Gieschen que nos corpora de consulta, sendo que no corpus de consulta geral estes padrões têm baixa ou quase nenhuma representatividade.

Gieschen apresenta dois padrões iguais aos de Folch, que parecía e me pareció, e três iguais aos de Herrero, que parecía, parecía que e no parecía. Sendo assim, esta tradutora não apresentou, entre os quatro primeiros padrões mais frequentes, nenhum padrão diferente dos TTs analisados.

Os padrões de Gieschen seguem, em sua maioria, o posicionamento de L1 + nódulo, um deles apenas com posicionamento diferente, nódulo $+\mathrm{R} 1$. As estruturas gramaticais observadas foram pronome relativo + verbo e verbo + pronome relativo, pronome pessoal + verbo 
e advérbio de negação + verbo e, assim como Herrero, Gieschen também apresenta predominância no uso do pronome relativo que tanto na posição de L1 como R1. Esses padrões assumem a função referencial com graus de imprecisão e, também, de expressão de atitudes pessoais. O Quadro 8 apresenta exemplos de colocações em HOD_Gieschen.

Quadro 8 - Exemplos de padrões de colocações com parec* em HOD_Gieschen

\begin{tabular}{|c|c|c|}
\hline $\mathbf{N}^{\mathbf{0}}$ & HOD_GIESCHEN & HOD_CONRAD \\
\hline 01 & $\begin{array}{l}{[. . .] \text { la posibilidad de un ataque }} \\
\text { repentino y de una carnicería o } \\
\text { algo por el estilo que parecía estar } \\
\text { en el aire fue recibida por mí como } \\
\text { algo agradable y reconfortante. }\end{array}$ & $\begin{array}{l}{[\ldots] \text { the possibility of a sudden onslaught }} \\
\text { and massacre, or something of the kind, } \\
\text { which I saw impending, was positively } \\
\text { welcome and composing. }\end{array}$ \\
\hline 02 & $\begin{array}{l}{[. . .] \text { pero parecía que ella pensaba }} \\
\text { recordarlo y llorarlo siempre. }\end{array}$ & $\begin{array}{l}{[\ldots] \text { she seemed as though she would }} \\
\text { remember and mourn forever. }\end{array}$ \\
\hline 03 & $\begin{array}{l}\text { Parecía que sus relaciones se ha- } \\
\text { bian visto muy interrumpidas por } \\
\text { varias causas. }\end{array}$ & $\begin{array}{l}\text { It appears their intercourse had been } \\
\text { very much broken by various causes. }\end{array}$ \\
\hline 04 & $\begin{array}{l}\text { Me pareció vislumbrar algo que se } \\
\text { movía delante de mí. }\end{array}$ & $\begin{array}{l}\text { I thought I could see a kind of motion } \\
\text { ahead of me. }\end{array}$ \\
\hline
\end{tabular}

Fonte: Castro (2016).

No exemplo 1 a tradutora optou pela expressão que parecía para a tradução de which I saw do TF, preferindo repetir uma forma flexionada de parec* para um excerto do texto em que não havia padrão com uma forma flexionada de seem*. No exemplo 2 o uso da expressão parecía que muda a estrutura da frase do TF e no exemplo 3 vê-se que a tradutora manteve o uso da colocação parecía que (pretérito imperfecto de parecer), ainda que o verbo do TF, appears, esteja no Simple Present.

Os padrões mostrados nos exemplos 1, 2 e 3 são colocações referenciais que descrevem, identificam e caracterizaram o sujeito, mantendo graus de imprecisão. Porém, no exemplo 4 me pareció foi usado para traduzir I thought, representando uma atitude pessoal, isto é, uma opinião epistêmica pessoal. Estes exemplos marcam algumas preferências desta tradutora. A Tabela 10 apresenta os padrões de colocações em HOD_Ingberg. 
Tabela 10 - Frequência absoluta e normalizada de colocações com parec* em HOD_Ingberg

\begin{tabular}{|c|c|c|c|c|c|}
\hline Fonte & $\begin{array}{l}\text { Número de } \\
\text { Itens }\end{array}$ & Padrão & $\begin{array}{l}\text { Número de } \\
\text { Ocorrências }\end{array}$ & $\begin{array}{c}\text { Frequência } \\
\text { normalizada } \\
\text { por } 1.000 \\
\end{array}$ & $\begin{array}{c}\text { Percentual de } \\
\text { ocorrências entre } \\
\text { padrões (\%) }\end{array}$ \\
\hline \multirow{4}{*}{ HOD_Ingberg } & \multirow{4}{*}{39.443} & Me pareció & 16 & 0,41 & 39,05 \\
\hline & & Que parecía & 12 & 0,31 & 29,52 \\
\hline & & Al parecer & 08 & 0,20 & 19,05 \\
\hline & & No parecía & 05 & 0,13 & 12,38 \\
\hline \multirow{4}{*}{$\begin{array}{c}\text { Corpus_Cons } \\
\text { (total) }\end{array}$} & \multirow{4}{*}{100.000 .000} & Me pareció & 665 & 0,01 & 33,33 \\
\hline & & Que parecía & 1.263 & 0,01 & 33,33 \\
\hline & & Al parecer & 1.356 & 0,01 & 33,33 \\
\hline & & No parecía & 337 & 0,00 & 0,00 \\
\hline \multirow{4}{*}{$\begin{array}{l}\text { Corpus_Cons } \\
\text { (ficção) }\end{array}$} & \multirow{4}{*}{4.769 .873} & Me pareció & 214 & 0,04 & 25,00 \\
\hline & & Que parecía & 328 & 0,07 & 43,75 \\
\hline & & Al parecer & 141 & 0,03 & 18,75 \\
\hline & & No parecía & 88 & 0,02 & 12,5 \\
\hline
\end{tabular}

Fonte: Castro (2016).

Na Tabela 10 o padrão mais recorrente é me pareció $(0,41)$. A frequência desta colocação nos corpora de consulta geral e de ficção é de 0,01 e de 0,04 , respectivamente. Desse modo, infere-se que se trata de um padrão de preferência em HOD_Ingberg. Além disso, nenhum TT apresentou número igual ou maior em relação à frequência normalizada do primeiro padrão, o que reforça a hipótese de que Pablo Ingberg tem preferência por esse padrão.

HOD_Ingberg apresenta que parecía, como segundo mais recorrente, com 0,31 de frequência normalizada, seguido de al parecer $(0,20)$. Assim como acontece em HOD_Folch, HOD_Ingberg apresenta uma preferência pelo padrão al parecer que, conforme já visto, trata-se de um padrão usual em corpus de textos jornalísticos. É importante ressaltar que em HOD_Ingberg todos os padrões encontrados tiveram maior frequência normalizada em relação aos corpora de consulta.

Os quatro padrões de colocações de Ingberg são formados a partir do posicionamento de L1 + nódulo, assim como em HOD_Folch. As estruturas gramaticais observadas foram pronome pessoal + verbo, pronome relativo + verbo, advérbio/advérbio de negação + verbo. Em relação às funções discursivas observam-se as mesmas já mencionadas nos padrões dos tradutores anteriores, isto é, trata-se de colocações que 
descrevem, caracterizam e identificam o sujeito e, alguns, de opiniões epistêmicas pessoais. O Quadro 9 traz os exemplos das colocações de Ingberg.

Quadro 9 - Exemplos de padrões de colocações com parec* em HOD_Ingberg

\begin{tabular}{c|l|l}
\hline $\mathbf{N}^{\mathbf{0}}$ & \multicolumn{1}{|c|}{ HOD_INGBERG } & \multicolumn{1}{c}{ HOD_CONRAD } \\
\hline $\mathbf{0 1}$ & $\begin{array}{l}\text { El costado de su cabeza golpeó } \\
\text { dos veces el timón, y el extremo de } \\
\text { lo que parecía una caña larga }[\ldots]\end{array}$ & $\begin{array}{l}\text { The side of his head hit the wheel twice, } \\
\text { and the end of what appeared a long cane } \\
{[\ldots]}\end{array}$ \\
\hline $\mathbf{0 2}$ & $\begin{array}{l}\text { No sé cómo impresionó a los otros: } \\
\text { a mi me pareció como si la niebla } \\
\text { misma hubiera aullado, }\end{array}$ & $\begin{array}{l}\text { I don't know how it struck the others: to } \\
\text { me it_seemed as though the mist itself had } \\
\text { screamed, }\end{array}$ \\
\hline $\mathbf{0 3}$ & $\begin{array}{l}\text { Al parecer, sin embargo, yo era } \\
\text { también uno de los Trabajadores, } \\
\text { con mayúscula, ¿saben? }\end{array}$ & $\begin{array}{l}\text { It appeared, however, I was also one of } \\
\text { the Workers, with a capital - you know. }\end{array}$ \\
\hline $\mathbf{0 4}$ & \begin{tabular}{l} 
La tierra no parecía terrenal. \\
\hline
\end{tabular}
\end{tabular}

Fonte: Castro (2016).

No primeiro exemplo observa-se que a colocação que parecía funciona como uma colocação referencial de descrição, bem como o exemplo 3 em que o grupo adverbial também funciona como colocação referencial usada para a tradução de It appeared. No exemplo 3 observa-se uma atitude pessoal em relação à descrição, o que envolve uma opinião. No exemplo 4 vê-se um complemento adjetival para o verbo cópula o que marca sua característica referencial.

Comparando os resultados dos quatro TTs entre si, verificou-se que HOD_Folch, HOD_Herrero e HOD_Gieschen apresentam como padrão mais recorrente que parecía, sendo o segundo mais recorrente em HOD_Ingberg. Observou-se que o padrão al parecer, que só aparece nos TTs de Folch e Ingberg, possui uma frequência maior nestes TTs, 0,26 e 0,20 , respectivamente. Ao analisarmos esse padrão no Corpus del Español, verificou-se que se trata de um padrão mais recorrente no corpus jornalístico do que no corpus ficcional, o que pode indicar uma tendência desses tradutores para o uso de padrões de colocações mais típicos de textos jornalísticos na tradução de textos ficcionais. 
HOD_Herrero tem parecía que como segundo padrão mais recorrente e HOD_Gieschen o apresenta como o terceiro. O padrão me pareció ocorre com frequência alta nos textos de Pablo Ingberg, Amália Gieschen e Borja Folch, sendo o primeiro mais recorrente em HOD_Ingberg $(0,41)$, o segundo em HOD_Gieschen $(0,28)$ e o quarto em HOD_Folch $(0,16)$.

Enquanto se observa uma predominância por padrões no pretérito (perfeito e imperfeito) nos TTs de uma forma geral, tem-se me parece como o terceiro padrão de colocação mais recorrente em HOD_Folch, com frequência de 0,18. Este resultado deve ser ressaltado, pois a preferência por este padrão em HOD_Folch pode ser um indicativo de escolhas diferenciadas, se considerarmos que esta é a tradução que possui a maior variação lexical e o menor número de frequência de itens lexicais com parec* (cf. CASTRO, 2016, 2018).

Os resultados indicam que alguns padrões podem ser equivalentes mais óbvios e próximos de padrões do texto-fonte e outros podem ser escolhas por equivalentes menos óbvios que, por sua vez, podem definir estratégias de tradução usadas pelos tradutores. A Tabela 11 apresenta os padrões de colocações com seem* em HOD_Conrad.

Tabela 11 - Frequência absoluta e normalizada de colocações com seem* em HOD_Conrad

\begin{tabular}{|c|c|c|c|c|c|}
\hline Fonte & $\begin{array}{l}\text { Número de } \\
\text { Itens }\end{array}$ & Padrão & $\begin{array}{l}\text { Número de } \\
\text { Ocorrências }\end{array}$ & $\begin{array}{c}\text { Frequência } \\
\text { normalizada } \\
\text { por } 1.000 \\
\end{array}$ & $\begin{array}{c}\text { Percentual de } \\
\text { ocorrências entre } \\
\text { padrões (\%) }\end{array}$ \\
\hline \multirow{4}{*}{ HOD_Conrad } & \multirow{4}{*}{38.792} & Seemed to & 46 & 1,19 & 61,66 \\
\hline & & It seemed & 14 & 0,36 & 18,65 \\
\hline & & That seemed & 09 & 0,23 & 11,92 \\
\hline & & Not seem & 06 & 0,15 & 7,77 \\
\hline \multirow{4}{*}{$\begin{array}{l}\text { Corpus_Cons } \\
\text { (total) }\end{array}$} & \multirow{4}{*}{100.000 .000} & Seemed to & 10.749 & 0,11 & 68,75 \\
\hline & & It seemed & 4.311 & 0,04 & 25,00 \\
\hline & & That seemed & 589 & 0,00 & 0,00 \\
\hline & & Not seem & 1329 & 0,01 & 6,25 \\
\hline \multirow{4}{*}{$\begin{array}{l}\text { Corpus_Cons } \\
\text { (ficção) }\end{array}$} & \multirow{4}{*}{15.909 .312} & Seemed to & 6.055 & 0,38 & 66,66 \\
\hline & & It seemed & 2.347 & 0,15 & 26,32 \\
\hline & & That seemed & 374 & 0,02 & 3,51 \\
\hline & & Not seem & 254 & 0,02 & 3,51 \\
\hline
\end{tabular}

Fonte: Castro (2016) 
Mayelli Caldas de Castro

O padrão mais recorrente em HOD_Conrad é seemed to, considerando a posição de R1. Stubbs (2003) aponta seemed to como o padrão mais recorrente em toda a obra de Conrad. Ao contrastar os achados de HOD com o corpus do BYU-BNC o pesquisador afirma que este padrão não é usual na língua em geral, tratando-se, portanto, de uso específico na obra de Conrad para a construção do tópico de incerteza.

Seemed to possui frequência normalizada de 1,19 em HOD, 0,11 no corpus de consulta geral e 0,38 no corpus de ficção. Ao compararmos estas frequências, verifica-se a diferença nitidamente, apesar de ser o padrão mais recorrente, entre os padrões de HOD_Conrad, nos corpora consultados, tendo em vista que a frequência no texto de Conrad é mais representativa, confirmando os resultados de Stubbs (2003) de que este é um padrão de escolha.

O segundo padrão é it seemed com o colocado na posição de L1 e frequência normalizada de 0,36 na obra, 0,04 no corpus geral e 0,15 no de ficção. Deve-se ressaltar que este padrão ocorre praticamente o dobro de vezes na obra de Conrad em relação ao corpus de ficção e pode-se dizer que não possui expressividade no corpus geral. Se considerarmos que parecía como equivalente mais óbvio em espanhol para that seemed, veremos que este é o primeiro padrão recorrente de colocação nos três primeiros TTs, o segundo em HOD_Ingberg, e that seemed o terceiro mais recorrente em HOD_Conrad, com frequência normalizada de 0,23 no $\mathrm{TF}$, ou seja, um número menor em relação à que parecía nos TTs.

É importante observar que de 46 ocorrências do padrão seemed to e 14 de it seemed, 11 ocorrências são "it seemed to"; e de 09 ocorrências de that seemed 08 são "that seemed to", ampliando o horizonte de análise e considerando a formação de um agrupamento lexical formado por três palavras a partir dos posicionamentos $\mathrm{L} 1+$ nódulo $+\mathrm{R} 1$, isto é, considerando a sobreposição dos colocados. É também relevante notar que isto não ocorreu para os padrões de colocações dos TTs.

O quarto padrão em HOD_Conrad foi not seem $(0,15)$. Este padrão poderia ter como equivalente o padrão no parecía em HOD_Herrero, HOD_Gieschen e HOD_Ingberg, uma vez que pode fazer parte do agrupamento lexical did not seem. Para essa confirmação expandiu-se a análise das linhas de concordância até o posicionamento de L2 para 
verificar quantas dessas ocorrências de not seem correspondem ao uso do pretérito nos TTs e verificou-se que todas as ocorrências de no parecía são equivalentes mais óbvios de did not seem no TF, instâncias de orações negativas com o verbo no Simple Past, confirmando a ocorrência de seu equivalente no parecía nos TTs.

Concluindo, verificou-se que a colocação que mais ocorreu nos $\mathrm{TTs}$, que parecía, é o equivalente mais óbvio de that seemed do TF, bem como que parecian (forma no plural) em HOD_Herrero. Ainda, me pareció pode ser um equivalente de it seemed to, considerando o pacote lexical com três palavras. O padrão (did) not seem do TF tem como equivalente no parecía nos TTs de Herrero, Gieschen e Ingberg.

Os padrões com parec* dos TTs que são equivalentes menos óbvios dos padrões mais recorrentes do TF foram al parecer, em HOD_Folch e HOD_Ingberg e me parece em HOD_Folch. Vale ressaltar que os quatro primeiros padrões mais recorrentes de cada tradução não foram os mesmos. Em suma, os resultados encontrados mostraram que ocorreram diferenças nas escolhas da tradução de formas flexionadas de seem* para o espanhol e que os tradutores apresentaram preferências diversas entre si. Viu-se que Folch foi o tradutor que apresentou escolhas mais diferenciadas em relação ao TF. Assim, a próxima seção apresenta uma versão do perfil estilístico individual dos tradutores.

\section{Perfil estilístico individual dos tradutores}

O Quadro 10 apresenta uma versão do perfil estilístico dos tradutores, construído com os resultados referentes aos padrões de colocações analisados neste estudo. 
Quadro 10 - Perfil estilístico individual dos tradutores

\begin{tabular}{|c|c|c|c|c|}
\hline Traço & HOD_FOLCH & $\begin{array}{l}\text { HOD_HERRE- } \\
\text { RO }\end{array}$ & $\begin{array}{l}\text { HOD_GIES- } \\
\text { CHEN }\end{array}$ & HOD_INGBERG \\
\hline $\begin{array}{c}\text { Colocações com } \\
\text { alg* }^{*}\end{array}$ & $\begin{array}{l}\text { - dois padrões re- } \\
\text { correntes no corpus } \\
\text { de ficção (algo que } \\
\text { - alguna vez) } \\
\text { - demais padrões } \\
\text { mais recorrentes no } \\
\text { TT do que nos cor- } \\
\text { pora de consulta }\end{array}$ & $\begin{array}{l}\text { - um padrão recor- } \\
\text { rente no corpus de } \\
\text { ficção (algo que) } \\
\text { - demais padrões } \\
\text { mais recorrentes } \\
\text { no TT do que } \\
\text { nos corpora de } \\
\text { consulta }\end{array}$ & $\begin{array}{l}\text { - um padrão } \\
\text { recorrente no } \\
\text { corpus de ficção } \\
\text { (algo que) } \\
\text { - demais padrões } \\
\text { mais recorrentes } \\
\text { no TT do que } \\
\text { nos corpora de } \\
\text { consulta }\end{array}$ & $\begin{array}{l}\text { - dois padrões } \\
\text { recorrentes no corpus } \\
\text { de ficção (algo que- } \\
\text { alguna vez) } \\
\text { - demais padrões mais } \\
\text { recorrentes no TT do } \\
\text { que nos corpora de } \\
\text { consulta }\end{array}$ \\
\hline $\begin{array}{c}\text { Colocações com } \\
\text { parec }^{*}\end{array}$ & $\begin{array}{l}\text { - um padrão com } \\
\text { alta frequência, } \\
\text { maior do que no } \\
\text { TT, no corpus de } \\
\text { ficção (me parece) } \\
\text { - um padrão co- } \\
\text { mum em corpus de } \\
\text { textos jornalísticos } \\
\text { (al parecer) } \\
\text { - demais padrões } \\
\text { mais comuns no TT } \\
\text { que nos corpora de } \\
\text { consulta }\end{array}$ & $\begin{array}{l}\text { - todos os padrões } \\
\text { mais frequen- } \\
\text { tes no TT que } \\
\text { nos corpora de } \\
\text { consulta }\end{array}$ & $\begin{array}{l}\text { - todos os padrões } \\
\text { mais frequen- } \\
\text { tes no TT que } \\
\text { nos corpora de } \\
\text { consulta }\end{array}$ & $\begin{array}{l}\text { - um padrão comum } \\
\text { em corpus de textos } \\
\text { jornalísticos (al } \\
\text { parecer) } \\
\text { - demais padrões } \\
\text { mais comuns no TT } \\
\text { que nos corpora de } \\
\text { consulta }\end{array}$ \\
\hline $\begin{array}{l}\text { Colocações } \\
\text { diferentes do } \\
\text { TF }\end{array}$ & $\begin{array}{l}\text { Alg* } \\
\text { Algo que } \\
\text { Algo asi } \\
\text { Parec* } \\
\text { Al parecer } \\
\text { Me parece }\end{array}$ & $\begin{array}{l}\text { Alg* } \\
\text { Algo de } \\
\text { Algo que } \\
\text { Parec** } \\
\text { Parecia que }\end{array}$ & $\begin{array}{l}\text { Alg* } \\
\text { Algo que } \\
\text { Parec* } \\
\text { Parecía que }\end{array}$ & $\begin{array}{l}\text { Alg* } \\
\text { Algo que } \\
\text { Parec* } \\
\text { Al parecer }\end{array}$ \\
\hline $\begin{array}{l}\text { Tendências } \\
\text { observadas }\end{array}$ & $\begin{array}{l}\text { - Escolhas de } \\
\text { padrões de coloca- } \\
\text { ções mais comuns } \\
\text { em textos ficcionais } \\
\text { do que os outros } \\
\text { tradutores } \\
\text { - Mais padrões de } \\
\text { colocações diferen- } \\
\text { tes do TF }\end{array}$ & $\begin{array}{l}\text { - Escolha de } \\
\text { padrões de colo- } \\
\text { cações diferentes } \\
\text { do TF em número } \\
\text { menor ao de Folch }\end{array}$ & $\begin{array}{l}\text { - Escolha de pa- } \\
\text { drões de coloca- } \\
\text { ções equivalentes } \\
\text { mais óbvios dos } \\
\text { padrões do TF }\end{array}$ & $\begin{array}{l}\text { - Escolha de padrões } \\
\text { de colocações equiva- } \\
\text { lentes mais óbvios dos } \\
\text { padrões do TF }\end{array}$ \\
\hline
\end{tabular}

Fonte: Castro (2016).

As escolhas relativas aos padrões de colocações com os nódulos analisados indicam preferências diversificadas para traduzir o mesmo item lexical ou padrões de colocações desse item, isto é, preferências estilísticas diferentes de cada tradutor. Estes resultados direcionam o estudo para a investigação dessas diferenças, isto é, as mudanças na tradução observadas na tradução destes itens. 


\section{Considerações Finais}

Os resultados da análise dos padrões de colocações mostraram que Folch é o tradutor que mais utilizou padrões de colocações comuns em corpus de textos de ficção e de textos jornalísticos. Ingberg também apresentou alguns padrões de colocações comuns em textos ficcionais e jornalísticos, porém Ingberg apresentou mais escolhas por padrões de colocações que são equivalentes mais óbvios daqueles do TF. Folch e Herrero foram os tradutores que apresentaram escolhas por padrões mais diferentes daqueles encontrados no TF, sendo Folch o tradutor com maior recorrência de padrões diferentes. Estes resultados mostraram que Folch e Herrero foram os tradutores com maior número de escolhas lexicais diferentes do $\mathrm{TF}$, ao passo que Gieschen e Ingberg apresentaram escolhas lexicais mais próximas do TF. Além disso, foi possível constatar que os tradutores realizaram escolhas divergentes para traduzir os mesmos padrões do TF.

Os resultados obtidos relativos aos padrões de colocações mostraram que, de uma forma geral, os padrões apresentados tanto nos TTs como no TF podem indicar preferências dos tradutores e do autor, pois a comparação com os corpora de consulta permitiu verificar que, na maioria dos casos, os padrões apontados foram utilizados com mais ênfase nos TTs e no TF do que nos corpora de consulta. Os resultados confirmaram a hipótese de Stubbs $(2003,2005)$ de que esses padrões foram escolhidos para o desenvolvimento de um dos principais tópicos de Heart of Darkness, a incerteza, e de que é possível identificar traços de estilo por meio da investigação de itens léxico-gramaticais.

\section{Referências}

BAKER, M. 2000. Towards a methodology for investigating the style of a literary translator. Target, Amsterdam, v. 12, no. 2, p. 241-266.

BERBER SARDINHA, T. 2004. Linguística de corpus. Barueri: Manole.

BERBER SARDINHA. 2009. Pesquisa em Linguística de Corpus com Wordsmith Tools. Campinas, SP: Mercado de Letras.

BIBER, D. et al. 2004. If you look at....: Lexical Bundles in University Teaching and Textbooks. Applied Linguistics. New York: Oxford University Press: 371-405. 
BLAUTH, T. 2015. A paisagem indizivel de duas traduções brasileiras de Heart of Darkness: uma análise de estilo com base em corpus. Dissertação (Mestrado em Estudos Linguísticos). Belo Horizonte: Faculdade de Letras da UFMG: $138 \mathrm{f}$.

CASTRO, M. C. 2016. O perfil estilístico de quatro tradutores de Heart of Darkness para o espanhol: uma investigação de mudanças de tradução (shifts in translation) baseada em padrões de itens lexicais de um corpus paralelo. Tese (Doutorado em Estudos Linguísticos). Belo Horizonte: Faculdade de Letras da UFMG: 178f.

CASTRO, M. C. 2018. O uso da lista de Consistência Detalhada (Detailed Consistency List) do Wordsmith Tools@ 6.0 para a investigação do perfil estilístico de quatro tradutores de Heart of Darkness para o espanhol. Texto Livre Linguagem e Tecnologia, Belo Horizonte, v.11, n. 1, p.1-23.

CHESTERMAN, A. 2007. Similarity Analysis and the Translation Profile. Amsterdam: John Benjamins: 53 - 66.

LEUVEN-ZWART, K. M. 1989. Translation and Original Similarities and Dissimilarities I. Target. Amsterdam: John Benjamins: 151- 181.

LEUVEN-ZWART, K. M. 1990. Translation and Original Similarities and Dissimilarities II. Target. Amsterdam: John Benjamins: 69- 95.

MAGALHÃES, C. M. 2014. ESTRA: Um corpus para o estudo do estilo da tradução. Florianópolis: Cadernos de Tradução, n 34: 248 - 271.

MAGALHÃES, C; ASSIS, R. C. 2010. Representação de atores sociais em corpus paralelo: Heart of Darkness e suas traduções para o português. In: COHEN, Maria Antonieta; LARA, Gláucia Muniz Proença. (Org.). Linguística, tradução, discurso. Belo Horizonte: Editora UFMG: 201-220.

MAGALHÃES, C. M.; CASTRO, M.C.; MONTENEGRO, M.S. 2013. Estilística tradutória: um estudo de corpus paralelo de uma tradução brasileira e uma tradução portuguesa de Heart of darkness. TradTerm, v. 21:11-29.

MONTENEGRO, M.S. 2015. O perfil de quatro tradutores portugueses de Heart of Darkness: um estudo do estilo do tradutor com base em corpus. Tese (Doutorado em Estudos Linguísticos). Belo Horizonte: Faculdade de Letras da UFMG: $178 \mathrm{f}$.

OLOHAN, M. 2004. Introducing Corpora in Translation Studies. Londres e Nova York: Routledge.

PEKKANEN, H. 2010. The Duet between the Author and the Translator: An Analysis of Style through Shifts in Literary Translation. Tese (Doutorado). Finlândia: Universidade de Helsinki. 
REAL ACADEMIA ESPAÑOLA. 2010. Nueva Gramática de La Lengua Española - Manual. Associación de Academias de La lengua Española. Espanha: Espasa Libros, S.L.U.

SALDANHA, G. 2011. Translator Style: methodological considerations. Manchester: St. Jerome Publishing, The Translator. Volume 17, Número 1: 25-50.

SALDANHA, G. 2011b. Emphatic Italics in English Translations: Stylistic Failure or Motivated Stylistic Resources? Meta: Translators' Journal. vol. 56, n. 2: 424-442. Disponível em http://id.erudit.org/ iderudit/1006185ar. Acesso em 15 de agosto de 2018.

SALDANHA, G. 2011c. Style of Translation: The Use of Foreign Words in Translations by Margaret Jull Costa and Peter Bush. In: KRUGER, A., WALLMACH, K., MUNDAY, J. (eds.). Corpus-Based Translation Studies Research and Applications. Continuum: 237 - 258.

SCOTT, M. 2012. WordSmith Tools version 6.0. Liverpool: Lexical Analysis Software.

SINCLAIR, J. 1991. Corpus, concordance, collocation. New York: Oxford University Press.

SINCLAIR, J. 2004. Trust the text: Language, corpus and discourse. London: Routledge.

STUBBS, M. 1995. Collocations and cultural connotations of common words. Linguistics and Education. Trier: University of Trier: 379390.

STUBBS, M. 2003. Conrad in the computer: examples of quantitative stylistic methods. Conrad, Concordance, Collocation: Heart of Darkness or light at the end of the tunnel? Language and Literature. Trier, Alemanha: Universidade de Birmingham: 5-24.

STUBBS, M. 2005. Conrad in the computer: examples of quantitative stylistic methods. Language and Literature. Volume 14. Número 5. Disponível em: http://lal.sagepub.com/cgi/content/abstract/14/1/5. Acesso em 15 de agosto de 2018.

TOURY, G. 1995. Descriptive Translation Studies and Beyond. Amsterdam: John Benjamins.

Recebido em: 02/08/2018

Aprovado em: 28/04/2019 